\title{
Photocurable acrylate-based composites with enhanced thermal conductivity containing boron and silicon nitrides
}

\author{
M. Sadej ${ }^{1}, H$. Gojzewski $^{2,3}$, P. Gajewski ${ }^{1}$, G. J. Vancso $^{3}$, E. Andrzejewska ${ }^{1 *}$ \\ ${ }^{1}$ Faculty of Chemical Technology, Poznan University of Technology, Berdychowo 4, 60-965 Poznan, Poland \\ ${ }^{2}$ Faculty of Technical Physics, Poznan University of Technology, Piotrowo 3, 60-965 Poznan, Poland \\ ${ }^{3}$ Materials Science and Technology of Polymers, Faculty of Science and Technology, University of Twente, \\ Drienerlolaan 5, 7522 NB Enschede, the Netherlands
}

Received 7 February 2018; accepted in revised form 10 April 2018

\begin{abstract}
Boron nitride $(\mathrm{BN})$ and silicon nitride $\left(\mathrm{Si}_{3} \mathrm{~N}_{4}\right)$ are very promising particulate fillers for production of photocurable composites dedicated to thermally conductive and electrically insulating protective coatings. Composites containing crosslinked methacrylate-based matrices filled with $\mathrm{BN}$ or $\mathrm{Si}_{3} \mathrm{~N}_{4}$ (in amounts up to $5 \mathrm{wt} \%$ ) were prepared in a fast in situ photocuring process with high conversion $(>90 \%)$. The monomers were polyethylene glycol dimethacrylate and monomethacrylate ( $50 / 50$ by weight mixture). Investigations included determination of properties of the monomer/filler compositions, photocuring kinetics and thermal, conductive and mechanical properties of the resulting composites. It was found that addition of the fillers improves polymerization kinetics and mechanical properties compared to the pure polymer matrix. Despite the very low loading level a substantial improvement in thermal conductivity was obtained: a 4-fold increase after addition of only $2 \mathrm{wt} \%$ of $\mathrm{Si}_{3} \mathrm{~N}_{4}$ and 2.5 -fold increase after addition of $0.5 \mathrm{wt} \%$ of BN. SEM and AFM imaging (with nanoscopic Young's modulus determination) revealed good matrix-filler adhesion for the both types of fillers, tendency of the particles to be preferentially located in the bulk rather than at the interface and formation of thermally conducting paths (for the $\mathrm{Si}_{3} \mathrm{~N}_{4}$ filler).
\end{abstract}

Keywords: polymer composites, boron nitride, silicon nitride, acrylates, photocuring

\section{Introduction}

Thermally conductive and electrically insulating materials are of a great importance from the scientific point of view, as well as for many applications in industry, and engineering. High thermal conductivity and electrical insulation are rarely found in one material, especially in polymers [1-3]. The intrinsic thermal conductivity of polymers is very low (typically $0.1-0.5 \mathrm{~W} /(\mathrm{m} \cdot \mathrm{K}))$, therefore it is necessary to enhance these properties for material used in special applications, e.g. protective coatings in the coating industry, 3D printing or electronic packaging.

In recent years much attention has been devoted to modification of coatings by fillers, several studies have been conducted to improve thermal conductivity of polymers, especially epoxy system [4-6]. One interesting possibility was to introduce inorganic ceramics as conductive fillers. In applications, that require both thermally conductive and electrically insulating materials, fillers like boron nitride $(\mathrm{BN})$ [6-9], aluminium nitride (AlN) [10, 11], silicon nitride $\left(\mathrm{Si}_{3} \mathrm{~N}_{4}\right)$ [12-14] or silicon carbide ( $\left.\mathrm{SiC}\right)[2,15$, $16]$ can be used in composite manufacturing $[2,17]$. For the applications where the electrical insulation is not required, thermally conductive additives, like graphite [16], graphene [18, 19], metal particles, and carbon nanotubes $[17,18]$ can be used. 
Ceramic fillers have lack of free electrons and the heat transfer is predominantly through phonons [20]. Effective phonic conduction requires strong bonds among the polymer matrix and the fillers. The phonon conduction is influenced by several processes, such as the number of phonon active modes, the boundary surface scattering or the length of the free path for the phonons.

The effective thermal conductivity of a composite containing inorganic particles is a function of the thermal conductivity of the components, particle loading level, interface, impurities, size effects, shape (geometric parameters of the contact area between particles), thermo-mechanical properties of matrix and thermal interfacial resistance [2]. The thermal contact resistance between filler particles depends on the properties of the components and the geometric parameters of the contact area between the fillers [21, 22]. Ineffective dispersion of the fillers in polymer matrix and agglomerates can lead to high thermal interfacial resistance and reduced thermal conductivity [20, 23].

Boron nitride $(\mathrm{BN})$ and silicon nitride $\left(\mathrm{Si}_{3} \mathrm{~N}_{4}\right)$ possess excellent properties, such as high thermal stability, electrical insulation and chemical resistance, and additionally have relatively high thermal conductivity coefficient values [14, 23-28]. Boron nitride is a structural analogue of carbon and has layered (hexagonal) or cubic structures [29]. The hexagonal $\mathrm{BN}$ is analogous to graphite due to layers consisting of rings of six alternating and covalently bound boron and nitrogen atoms [30]. The layers form stacks as a result of van der Waals interactions. Crystal growth rates are, as a result, anisotropic, i.e. faster in planar direction, yielding boron nitride particles with high aspect ratios. Related to structural anisotropy, crystal lattice dependent properties, such as thermal conductivity, also become anisotropic. Values of thermal conductivity range between 200 $300 \mathrm{~W} /(\mathrm{m} \cdot \mathrm{K})$ along the plane of stacks, and up to several of $\mathrm{W} /(\mathrm{m} \cdot \mathrm{K})$ perpendicular to the plane of stacks [31]. Thus, the orientation of particles is of particular importance in obtaining materials with high thermal conductivity, for instance, in polymer composites. Therefore, the reported values of the thermal conductivity vary strongly depending on the literature source [27, 32]. Also mechanical properties of boron nitride, for instance, Young's modulus, vary significantly, depending not only on the polymorphic form, but also on the testing direction. For hexagonal and cubic BN forms, the bulk Young's moduli typically are of the order of 35 and $400 \mathrm{GPa}$, respectively [33]. $\mathrm{BN}$ particles have been used in the preparation of thermally conductive composites as they form conductive pathways in the polymer matrix [23], and as fillers in various polymer matrices, such as linear lowdensity polyethylene [34], polypropylene [35], poly (butylene terephthalate) [9], epoxy resin [23, 36, 37] silicone rubber [38], polyimide [31], polysilazane [39] or poly (methyl methacrylate) [8].

Nanosized $\mathrm{Si}_{3} \mathrm{~N}_{4}$ particles are also used for various applications because of their high mechanical strength, high fracture toughness, low dielectric constant, and high thermal conductivity $[13,40]$. For instance, $\mathrm{Si}_{3} \mathrm{~N}_{4}$ particles have been used/proposed for the improvement of mechanical properties, wear resistance and thermal-shock resistance of the matrix polymers [13, 14]. Recently, it has been shown that $\mathrm{Si}_{3} \mathrm{~N}_{4}$ can be as effective as $\mathrm{BN}$ in the heat transfer due to several modifications that can be applied, for example, the enhancement of the $\beta / \alpha$ ratio of the $\mathrm{Si}_{3} \mathrm{~N}_{4}$ phases [12]. Some experimental and theoretical studies reported that the upper limit of the thermal conductivity for $\beta-\mathrm{Si}_{3} \mathrm{~N}_{4}$ is around $400 \mathrm{~W} /(\mathrm{m} \cdot \mathrm{K})$. This value drops to around $100 \mathrm{~W} /(\mathrm{m} \cdot \mathrm{K})$ for $\alpha-\mathrm{Si}_{3} \mathrm{~N}_{4}[41,42]$. The bulk Young's modulus is a weak function of the $\alpha$ and $\beta \mathrm{Si}_{3} \mathrm{~N}_{4}$ phases, and its typical value is within the range of 220-280 GPa [43]. Boron nitride and silicon nitride particles, thus represent extremely promising polymer fillers, and have the potential to significantly improve the overall properties of 'micro' and 'nano' composites, especially their ability to transfer heat.

Polymer composites can be prepared by mixing the polymer with the filler or by in situ methods [44]. The in situ preparation consists of dispersing an inorganic filler in a monomer followed by polymerization. When thermoplastic matrices are used, the composites are usually prepared by traditional methods (melt or solvent blending, etc.) [23, 38, 45]. The in situ curing (which can effectively improve the uniform dispersion of inorganic fillers in polymeric matrix) has been applied mainly for thermosets, like epoxy, polybenzoxazine, polyimide, etc. For example, in the case of epoxy-based materials highly filled (up to 60\%) with BN (often surface-modified) the conductivity increased even several times compared to the matrix, depending on the filler content and its modification $[23,32,37]$. On the other hand, there are only few reports where chain polymerization was applied; the 
process was induced by thermal initiators (it needs elevated temperatures and long reaction times) [46]. Prepared in this way poly(methyl methacrylate) (PMMA) filled with about $10 \%$ of $\mathrm{Si}_{3} \mathrm{~N}_{4}$ showed an increase in thermal conductivity by about $28 \%$ [46]. Thermal conductivity of PMMA filled with $16 \%$ of BN was 1.8 times higher than that of pure PMMA [8]. An especially interesting in situ method is photopolymerization, which can proceed rapidly at ambient temperature. The use of light enables one to control the reaction rate with high precision, as start and end points are well defined by lighting on/off. In addition, reactions take place only in irradiated areas, which enables spatial control [47]. These advantages of photopolymerization make it an attractive method for the design and development of new materials with improved thermal properties. Until now photoinitiation has been applied only for the cationic curing of an epoxy resin filled with BN nanotubes [3] (an increase in thermal conductivity at $1.5 \%$ of loading reached about $45 \%$ ) and very recently, in preparation of composites from thermosetting acrylic monomers (not defined) filled with surface modified $\mathrm{BN}$ [48].

In this work we present the results of investigations of the methacrylate-based composites with enhanced thermal conductivity, prepared by the in situ photopolymerization method. Our investigations were addressed mainly to production of photo-curable protective coatings combining enhanced thermal conductivity with improved mechanical properties as well as to other applications of photocurable compositions. Generally, polymer coatings have very low thermal conductivity and can be damaged by high temperatures (e.g. heat shock) [49]. Thermally conductive coating offers excellent heat transfer throughout the entire coated surface, while providing exceptionally high electrical insulation. Thermal conductivity benefits also adhesion to the substrate. However, the amount of filler in photo-curable formulation must be kept low due to light scattering that reduces the depth of cure (important is refractive index ratio between the filler and the organic matrix) and to prevent too high viscosity increase in viscosity, which is disadvantageous in the production of coatings. The improvement of thermal conductivity in the present work was achieved by the use of two types of nitride fillers: a micro-sized flake-shaped hexagonal $\mathrm{BN}$ and nano-sized $\mathrm{Si}_{3} \mathrm{~N}_{4}$ with spherical particles. It should be stressed that there are no reports about $\mathrm{Si}_{3} \mathrm{~N}_{4}$-containing acrylate-based composites prepared in an in situ process as well as those presenting deeper insight into the influence of the both nitrides on the photocuring kinetics. Therefore, our investigations included characterization of the monomer/filler composition, study of the kinetics of the photocuring process, determination of thermal, conductive and mechanical properties of the resulting composites and observation of the morphology of the composites (with nanoscopic Young's modulus determination).

The model matrix was based on a 50/50 by weight mixture of polyethylene glycol dimethacrylate (PEGDM) and polyethylene glycol monomethacrylate (PEGMM); such a composition enables to perform detailed kinetic measurements of the curing process and ensures good mechanical properties of the final polymer [50].

\section{Experimental}

\subsection{Materials}

The monomers, polyethylene glycol dimethacrylate with $M_{\mathrm{n}}=550 \mathrm{~g} / \mathrm{mol}(\mathrm{PEGDM})$ and polyethylene glycol monomethacrylate with $M_{\mathrm{n}}=360 \mathrm{~g} / \mathrm{mol}$ (PEGMM) were purchased from Aldrich and were purified by column chromatography before use. The boron nitride is the $\mathrm{HeBoFill}{ }^{\circledR} 641$ product from HENZE Nitride Products (Germany); it has hexagonal particles $(12 \mu \mathrm{m}$ median particle size) with a specific surface area $7 \mathrm{~m}^{2} / \mathrm{g}$. Silicon nitride supplied by Sigma Aldrich (product no. 634581) is an amorphous powder consisting of spherical particles with the following characteristics: average particle diameter $<50 \mathrm{~nm}$, specific surface area: $103-123 \mathrm{~m}^{2} / \mathrm{g}$. The fillers were dried at $110^{\circ} \mathrm{C}$ for $2 \mathrm{~h}$ before use. 2,2-dimethoxy-2-phenylacetophenone (Irgacure 651) was used (purchased from Aldrich) as the photoinitiator.

\subsection{Sample preparation}

The $50 / 50$ by weight monomer mixture was prepared and the fillers were added: $0.2-5 \mathrm{wt} \%$ of boron nitride or silicon nitride; the photoinitiator concentration was $0.2 \mathrm{wt} \%$ (based on the monomer content). The formulations were homogenized by ultrasonication through 2-20 hours to reach good levels of dispersion (no sedimentation). All monomer/filler formulations with varying percentages of $\mathrm{BN}$ and 
$\mathrm{Si}_{3} \mathrm{~N}_{4}$ appeared to be optically opaque, but they formed stable dispersions. The stability of the dispersions was about one week.

\subsection{Viscosity}

Viscosities of photocurable systems were measured with a DV-II + PRO Brookfield Digital Viscometer $\left(25^{\circ} \mathrm{C}, 0-600 \mathrm{1} / \mathrm{s}\right.$, cone-and-plate geometry).

\subsection{FTIR spectra}

The surface chemistry of the raw fillers (powder) and cured composites containing $\mathrm{BN}$ and $\mathrm{Si}_{3} \mathrm{~N}_{4}$ particles was characterized using a Fourier Transform Infrared Spectrometer (ATR-FTIR, Nexus Nicolet model 5700 spectrometer Thermo Fisher Scientific, USA) equipped with a ZnSe crystal ATR accessory. Spectra were acquired at $41 / \mathrm{cm}$ resolution as an average 64 scans. The spectrum in the 4000 to $6001 / \mathrm{cm}$ range was recorded.

\subsection{Photopolymerization kinetics}

Reaction rate profiles (enabling determination of the reaction rates $R_{\mathrm{p}}$ and conversion degrees $p$ ) were measured by DSC under isothermal conditions at $25.00 \pm 0.01^{\circ} \mathrm{C}$ in a high-purity argon atmosphere $\left(<0.0005 \%\right.$ of $\left.\mathrm{O}_{2}\right)$ using a Pyris 6 instrument (PerkinElmer) equipped with a lid specially designed for photochemical measurements. The $2 \mathrm{mg}$ samples were polymerized in open aluminium pans. The polymerizations were initiated using light from a LED Hamamatsu LC-L1 lamp ( $\lambda_{\max }=365 \mathrm{~nm}$, light intensity at the sample pan position $2.75 \mathrm{~mW} / \mathrm{cm}^{2}$ ). All photopolymerization experiments were conducted at least in triplicate. The reproducibility of the kinetic results was about $\pm 3 \%$.

\subsection{Thermal properties}

Glass transition temperatures $T_{\mathrm{g}}$ of the investigated systems were determined using differential scanning calorimetry (DSC1 Mettler Toledo instrument). Measurements were conducted under nitrogen atmosphere at heating rates of $10^{\circ} \mathrm{C} / \mathrm{min}$. $T_{\mathrm{g}}$ values were evaluated from the second run of DSC measurements over a temperature range of -80 to $40^{\circ} \mathrm{C}$ as the midpoint of the step-transition found for each sample. The specimens for the DSC test were prepared in the same way as the samples for mechanical characterization. Thermogravimetric analysis (TGA) (the thermal resistance) was investigated with TG 209 F3 Tarsus thermogravimetric analyser (NETZSCH-Geratebau
$\mathrm{GmbH}$, Germany). $10 \mathrm{mg}$ samples were heated in $\mathrm{Al}_{2} \mathrm{O}_{3}$ crucibles from 40 to $600^{\circ} \mathrm{C}$ at a scan rate of $10^{\circ} \mathrm{C} / \mathrm{min}$ under nitrogen atmosphere (purge of $10 \mathrm{~mL} / \mathrm{min}$ of $\mathrm{N}_{2}$ protection gas and $20 \mathrm{~mL} / \mathrm{min}$ of $\mathrm{N}_{2}$ sample gas).

\subsection{Mechanical properties}

The samples for mechanical tests were cured in a two-part stainless steel mold (type 1A tensile test bar according to ISO 3167). The photocurable formulations were placed, covered with poly(ethylene terephthalate) foil and irradiated with the whole spectrum of the Dymax UV 5000 Flood lamp for 300 seconds. The mechanical properties were investigated at $25^{\circ} \mathrm{C}$. The tensile properties were measured according to PN-EN ISO 527-2:1998 (crosshead speed of $5 \mathrm{~mm} / \mathrm{min}$ ) with a Zwick/Roell universal testing machine model Z020 (Zwick GmbH \& Co. KG, Germany). Shore $\mathrm{D}$ hardness values were measured according to DIN 53505.

\subsection{Thermal diffusivity and conductivity measurements}

Thermal diffusivity was determined according to the modified Angstrom method. The operating principles of the device as well as the method of determination of the thermal diffusivity of composites has been described in ref. [51]. This technique involves heating the sample with a microheater supplied with a sinusoidal variable voltage (changing voltage in the range $0-30 \mathrm{~V}$ ). The temperature along the sample is registered with temperature sensors (Pt 1000-RTD). The value of the thermal diffusivity $\left(D_{\mathrm{f}}\right)$ can be calculated using Equation (1):

$D_{\mathrm{f}}=\frac{\pi \cdot l^{2}}{2 \cdot\left(t_{2}-t_{1}\right) \cdot \ln \frac{\Delta T_{1}}{\Delta \mathrm{T}_{2}}}$

where $D_{\mathrm{f}}$ is thermal diffusivity $\left[\mathrm{m}^{2} / \mathrm{s}\right], l$ is distance between the RTD sensors, $t_{1}$ and $t_{2}$ are time periods when the maximum temperature in individual sensors is achieved, $\Delta T_{1}, \Delta T_{2}$ are differences between the maximum temperature and ambient temperature. On the basis of the obtained diffusivity results, thermal conductivity $\left(\lambda_{\mathrm{f}}\right)$ was estimated based on Equation (2):

$\lambda_{\mathrm{f}}=D_{\mathrm{f}} \cdot C_{\mathrm{p}_{\mathrm{f}}} \cdot \rho_{\mathrm{f}}$

where $D_{\mathrm{f}}$ is thermal diffusivity $\left(\left[\mathrm{m}^{2} / \mathrm{s}\right]\right.$, calculated from Equation (1)), $C_{\mathrm{p}_{\mathrm{f}}}$ is specific heat $[\mathrm{J} /(\mathrm{K} \cdot \mathrm{kg})]$, and $\rho_{\mathrm{f}}$ is density $\left[\mathrm{kg} / \mathrm{m}^{3}\right]$. 
Specific heat of the polymer matrix was determined by DSC (DSC1 Mettler Toledo instrument). Specific heats of boron nitrate and silicon nitrate were taken from literature: 600 (http://www.ioffe.ru/SVA/NSM/ Semicond/BN/index.html) and $650 \mathrm{~J} /(\mathrm{K} \cdot \mathrm{kg})(\mathrm{http} / / /$ www.syalons.com/advanced-ceramic-materials/silicon-nitride-and-sialon-ceramics/syalon-101/), respectively. The theoretical values of specific heat $\left(C_{\mathrm{p}_{\mathrm{f}}}\right)$ of the composites were calculated according to the rule of mixture (Equation (3)) [31]:

$C_{\mathrm{p}_{\mathrm{f}}}=C_{\mathrm{p}_{\mathrm{m}}} \cdot \phi_{\mathrm{wt}}+C_{\mathrm{p}_{\mathrm{fil}}} \cdot\left(1-\phi_{\mathrm{wt}}\right)$

where $C_{\mathrm{p}_{\mathrm{m}}}$ and $C_{\mathrm{p}_{\mathrm{fil}}}$ are specific heats of the polymer matrix and the filler, respectively $[\mathrm{J} /(\mathrm{K} \cdot \mathrm{kg})], \phi_{\mathrm{wt}}$ is the mass fraction of the polymer matrix in the composite.

Additionally, for composites containing $5 \mathrm{wt} \%$ of the fillers, direct measurements of thermal conductivity were carried out using a home-made setup containing a commercial (thin film) heat flux HFS-4 sensor retrofitted with DPi-32 digital process indicator (Omega Engineering Inc.) and dual input digital temperature meters (Fluke 52 II) [52] (calculations were based on the steady state Fourier's law).

\subsection{SEM}

A $5 \mathrm{kV}$ voltage scanning electron microscopy (SEM) (LEO 1530 Gemini, Zeiss, Germany) was used to obtain micrographs of $\mathrm{BN}$ and $\mathrm{Si}_{3} \mathrm{~N}_{4}$ particles, the neat matrix, as well as their respective composites. The applied working distance was $2-4 \mathrm{~mm}$. Polymer-based specimens were fractured under liquid nitrogen and imaged close to the center of the crackedge, i.e. on a top (free surface) section and on the side (indicating the morphology of the bulk).

\subsection{AFM}

Topology and Young's modulus maps were obtained in the PeakForce Quantitative Nanomechanical Mapping (QNM) mode by the Multimode 8 AFM retrofitted with the NanoScope $\mathrm{V}$ controller (Bruker, USA). In the PeakForce QNM mode the information about the tip-sample interactions can be obtained and evaluated in real-time by collecting force-distance curves and processing them simultaneously to yield estimates, for example, for elastic modulus, adhesion and deformation [53].

A FESPA-V2 (Bruker, USA) silicon cantilevers (nominal resonance frequency $75 \mathrm{kHz}$ and spring constant
$2.8 \mathrm{~N} / \mathrm{m}$ ) were used with a nominal tip-end radius of $8 \mathrm{~nm}$. The AFM piezo was oscillated at $1 \mathrm{kHz}$ and force-distance curves were captured each time the AFM tip tapped on the sample surface, i.e. at each pixel. The resolution $512 \times 512$ or $256 \times 256$ pixels was typically obtained, also representing the number of collected force-distance curves. Cantilever sensitivity was determined following a standard force spectroscopy recipe on a Piranha-cleaned $<100>$ silicon wafers; a slope of the approach part of forcedistance curves was measured. The value of the cantilever spring constant was determined by the thermal tune method $[54,55]$. The spring constant of the cantilevers used in this study ranged within 1.91$2.08 \mathrm{~N} / \mathrm{m}$. The cantilever deflection sensitivity was later adjusted again, taking into account the sine wave modulation of the cantilever in the PeakForce QNM mode.

The values of Young's moduli were determined with reference to a material of a known Derjaguin-MullerToporov (DMT) elastic modulus by using so-called 'relative method' based on a simplified DMT formalism [56, 57]. In the 'relative method' mechanical properties of a sample under investigation are compared to a known, well-defined reference sample. As reference sample we used polystyrene films with Young's modulus of $2.7 \mathrm{GPa}$ (provided by Bruker, USA) [53].

The free surface of all samples were measured in air, at a stable humidity $(40 \%)$ and temperature $\left(21.0^{\circ} \mathrm{C}\right)$. The indentation depth (sample deformation) was controlled - depending on the sample - to be typically between 3 and $8 \mathrm{~nm}$ [56]. The image processing and the data evaluation were performed with the NanoScope 8.15 and the NanoScope Analysis 1.80 software, respectively. The ScanAsyst panel of the NanoScope 8.15 software was set to 'individual' to minimize the influence of software auto-optimization on the collected data.

\section{Results and discussion}

Investigations were performed for a series of compositions containing $0,0.2,0.5,1,1.5,2$ and $5 \mathrm{wt} \%$ of the fillers. This level of the filler content is low compared to that used in thermally conductive composites produced by processing from thermoplastic materials or by some in situ methods; in such cases the filling level reaches often tens of percent, e.g. in refs. $[9,25,31,37]$. The low filler concentration in our work resulted from two facts: (i) mentioned 
earlier significant light scattering at higher filler contents which worsen the reaction kinetics and (ii) reduced mechanical properties. However, as will be shown later, even so low filler content enables significant increase in thermal conductivity of the resulting composites.

The fillers used in this work were not surface-modified. The lack of modification can be economically advantageous if positive results are obtained.

The photocurable compositions were characterized before the curing process (by viscosity measurements), during the polymerization (curing kinetics) and after the curing (by glass transition, spectral characteristics, mechanical properties, thermal diffusivity and conductivity as well as morphology of the composites).

\subsection{Viscosity}

Measurements of viscosity of the two-component mixtures as a function of their composition is an important characteristics for applications as coatings and for investigation of the polymerization kinetics. Figure 1 presents the viscosity of the monomer/filler

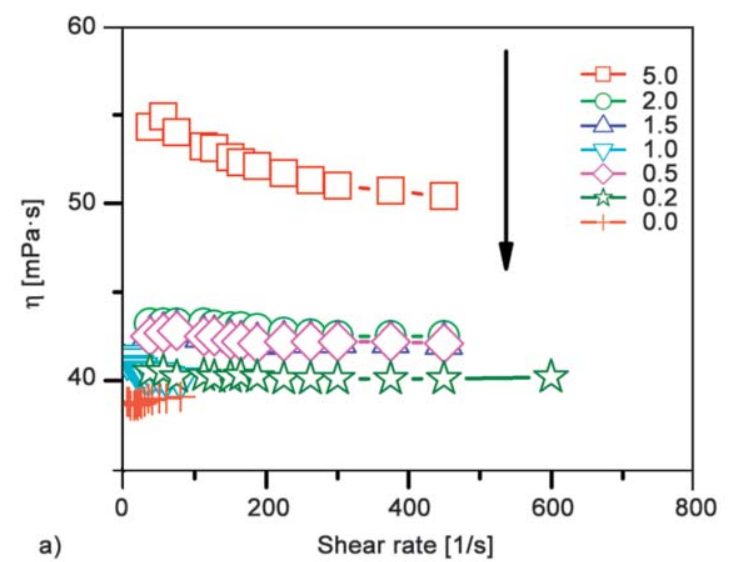

dispersions as a function of the shear rate and the filler content.

The measurements were made at $25^{\circ} \mathrm{C}$, which was also the temperature of kinetic studies and composite preparation. The viscosity of the neat monomer mixture exhibits Newtonian behavior; such a behavior is observed also for $\mathrm{BN}$-containing formulations except the one with the highest loading value ( $5 \mathrm{wt} \%$ ). In the case of $\mathrm{Si}_{3} \mathrm{~N}_{4}$-containing formulations the non-Newtonian behavior begins to appear already at about $1 \mathrm{wt} \%$ filler content; moreover, the increase in viscosity with the filler content is much stronger, as can be seen in Figure 1c. The rise of viscosity mainly stems from the interfacial friction (for filler/filler and filler/dispersing medium contacts). The excellent lubrication properties of $\mathrm{BN}$ ensure low increase in viscosity which can be also one of the reasons of lower viscosities of $\mathrm{BN}$-containing formulations. Other possible reason is smaller size of $\mathrm{Si}_{3} \mathrm{~N}_{4}$ particles. At a given loading the number of $\mathrm{Si}_{3} \mathrm{~N}_{4}$ particles in a formulation is higher compared to $\mathrm{BN}$ particles. This results in more particle-particle interactions and an increased resistance to flow.

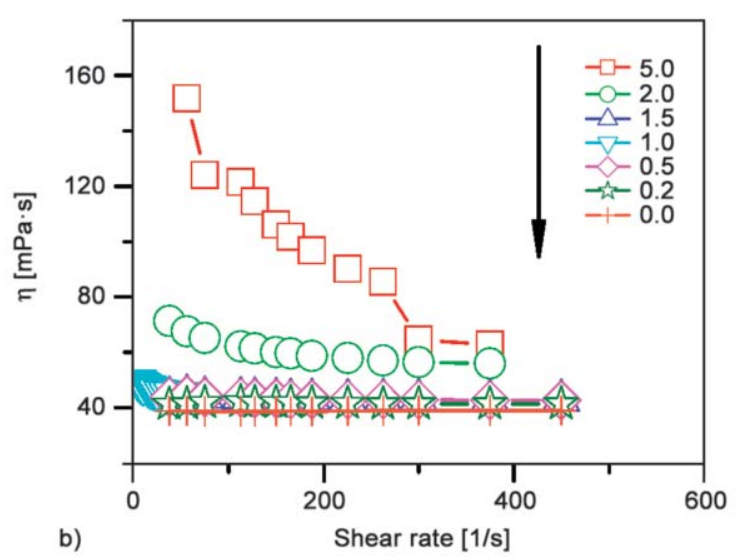

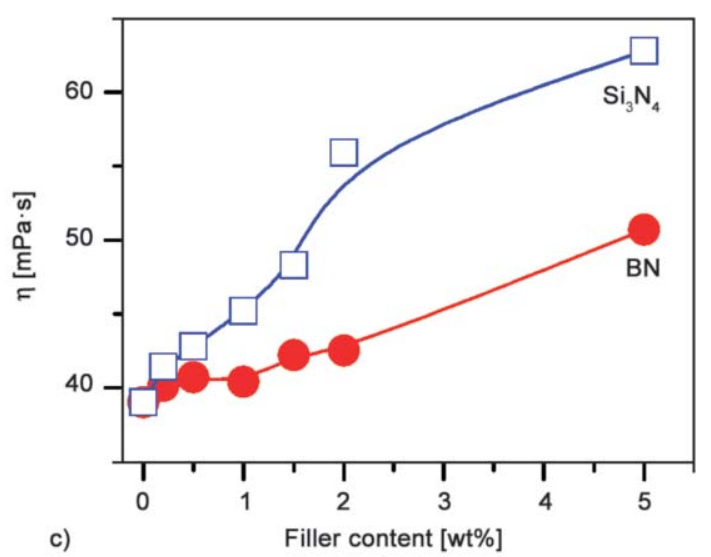

Figure 1. Viscosity of formulation as a function of the shear rate and the filler content at $25^{\circ} \mathrm{C}$; (a) $\mathrm{BN}$, (b) $\mathrm{Si}_{3} \mathrm{~N}_{4}$, (c) viscosity at the shear rate $\sim 3751 / \mathrm{s}$. Numbers indicate filler content in $\mathrm{wt} \%$. The lines are guides for the eye. 
Stronger interactions between $\mathrm{Si}_{3} \mathrm{~N}_{4}$ particles cause also that in the non-Newtonian ranges (for loadings $>1 \mathrm{wt} \%)$ the zero shear viscosity increases dramatically. Higher viscosities of $\mathrm{Si}_{3} \mathrm{~N}_{4}$-containing formulation can result also from filler/monomer interactions.

\subsection{FTIR-ATR spectra}

Comparison of FTIR-ATR spectra of the raw BN filler, the matrix and the polymer composites showed that there are no shifts of the positions of the absorption peaks. This could suggest that possible interactions of $\mathrm{BN}$ with the polymer matrix are rather low. However, it should be taken into account that BN particles are macrosized which causes that the contact surface area between the filler (at its low content) and the matrix is not large. Therefore, the number of interacting groups will not be high and interactions may not be reflected in the spectrum.

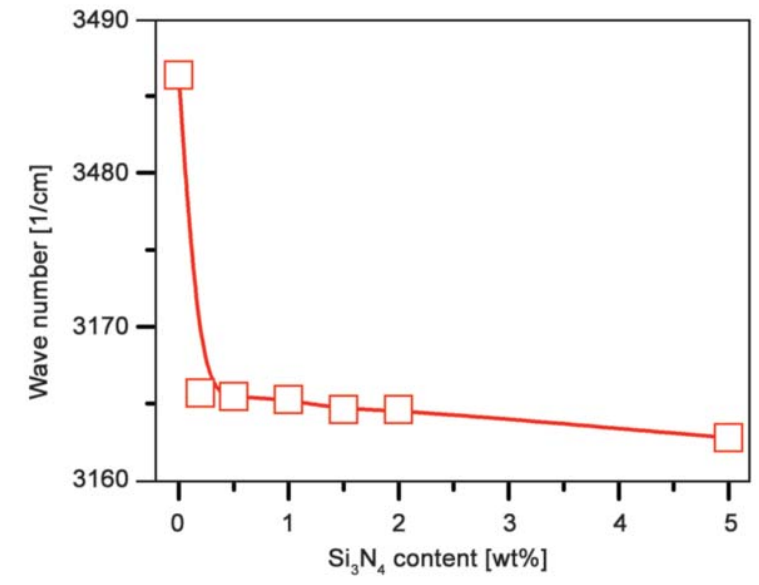

Figure 2. The position of the maximum of the $\mathrm{OH}$ absorption band of the polymer matrix as a function of the $\mathrm{Si}_{3} \mathrm{~N}_{4}$ content in the composite.

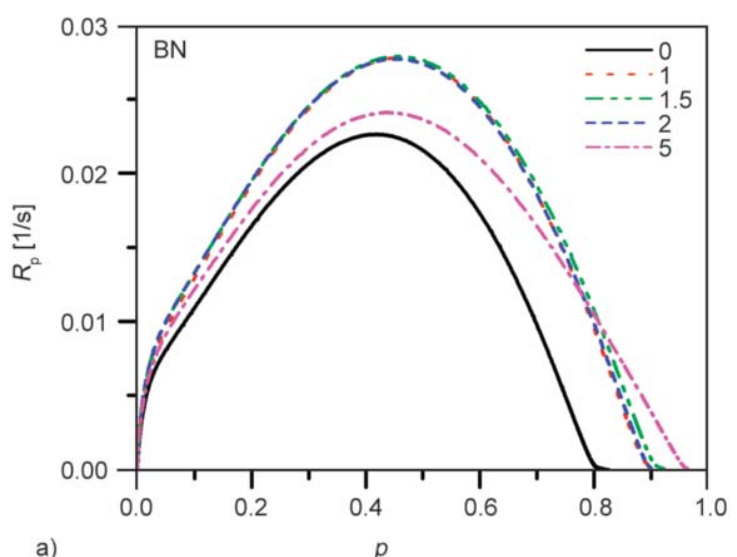

On the other hand, in the spectra of the composites containing the nanosized $\mathrm{Si}_{3} \mathrm{~N}_{4}$ (much larger surface contact with the matrix) a red-shift by about $101 / \mathrm{cm}$ of the position of the absorption band of the $-\mathrm{OH}$ group derived from the polymer matrix is observed (Figure 2). This points to interactions between the matrix and the filler.

\subsection{Photopolymerization kinetics}

The photopolymerization kinetics were followed for systems containing varying amounts of the fillers. The reactions rates $R_{\mathrm{p}}$ as functions of the double bond conversion $p$ are shown in Figure 3. The time needed to reach the final conversion $p^{\mathrm{f}}$ was $360 \mathrm{sec}$ under the polymerization conditions used.

Photopolymerization kinetics of the 50/50 mixture of the dimethacrylate and monomethacrylate monomer is analogous to the behaviour of the multifunctional monomers. The shape of the kinetic curves is characteristic for a crosslinking polymerization with immediate onset of autoacceleration, occurrence of the maximum polymerization rate $R_{\mathrm{p}}^{\max }$ and incomplete final conversion of double bonds $p^{\mathrm{f}}$ [58]. The maximum polymerization rate $R_{\mathrm{p}}^{\max }$ appears at $\sim 45 \%$ of double bond conversion. At this reaction stage a change in the dominant termination mechanism takes place: from termination controlled by translational diffusion to termination controlled by reaction diffusion [58].

Addition of $\mathrm{BN}$ or $\mathrm{Si}_{3} \mathrm{~N}_{4}$ influences the polymerization kinetics causing changes in $R_{\mathrm{p}}$ and $\mathrm{pf}$ and in the conversion at which $R_{\mathrm{p}}^{\max }$ appears, $p_{\mathrm{R}_{\mathrm{m}}}$ (Figure 4). $R_{\mathrm{p}}^{\max }$ at first increases with the filler content and then reaches the highest value for formulations containing 1.5 to $2 \mathrm{wt} \%$ of the both fillers; further increase in

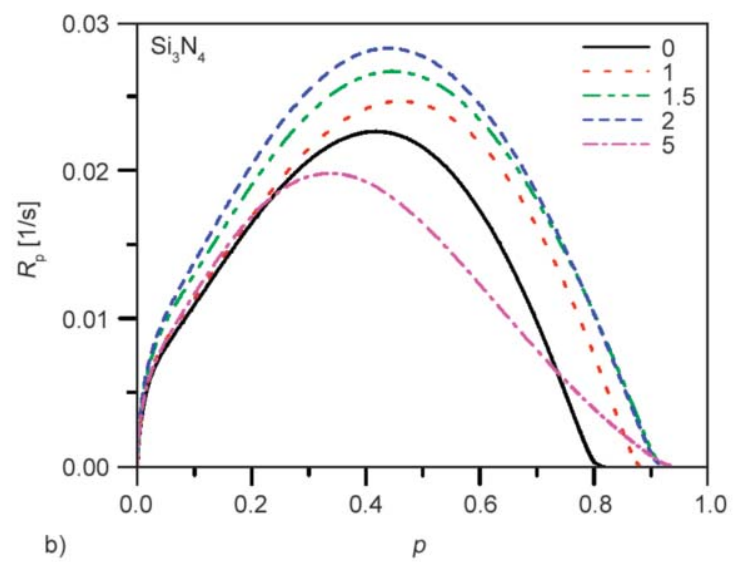

Figure 3. The dependence of the polymerization rate $R_{\mathrm{p}}$ on double bond conversion $p\left(\right.$ at $\left.25^{\circ} \mathrm{C}\right)$ for: (a) monomer/BN, (b) monomer $/ \mathrm{Si}_{3} \mathrm{~N}_{4}$ formulations. The numbers indicate the filler content (in wt $\%$ ). 
the filler loading reduces the values of $R_{\mathrm{p}}^{\max }$. In the classical approach both the increase and the decrease of the $R_{\mathrm{p}}^{\max }$ value can be related to the viscosity of the system. The acceleration of the polymerization is often associated with enhanced diffusional limitations of macroradicals which suppress the termination process; this increases both $R_{\mathrm{p}}$ as well as $R_{\mathrm{p}}^{\max }$. This is related to classical kinetics as the termination rate coefficient $\mathrm{ktb}$ is inversely proportional to the viscosity $(\mathrm{ktb} \sim 1 / \eta)$, and the polymerization rate $R_{\mathrm{p}}$ is related to the termination rate coefficient as $R_{\mathrm{p}}$ $\sim 1 /\left(k_{\mathrm{t}}^{\mathrm{b}}\right)^{0.5}[59]$. On the other hand, high values of viscosity lead to earlier appearance of the reaction diffusion controlled termination (decrease of $p_{\mathrm{R}_{\mathrm{m}}}$ value) and shift of the onset of the diffusion-limited propagation to lower conversion (reduction of $R_{\mathrm{p}}^{\max }$ ). However, in our systems the measured viscosity is a macroscopic factor and the kinetics cannot be related directly to it. The amounts of the fillers added are low; therefore, the reaction has to occur mainly in the pure monomer phase. The fact that the fillers affect the polymerization kinetics seems to suggest the influence of the filler/monomer interphase. Interaction of polymer macroradicals with the filler surface
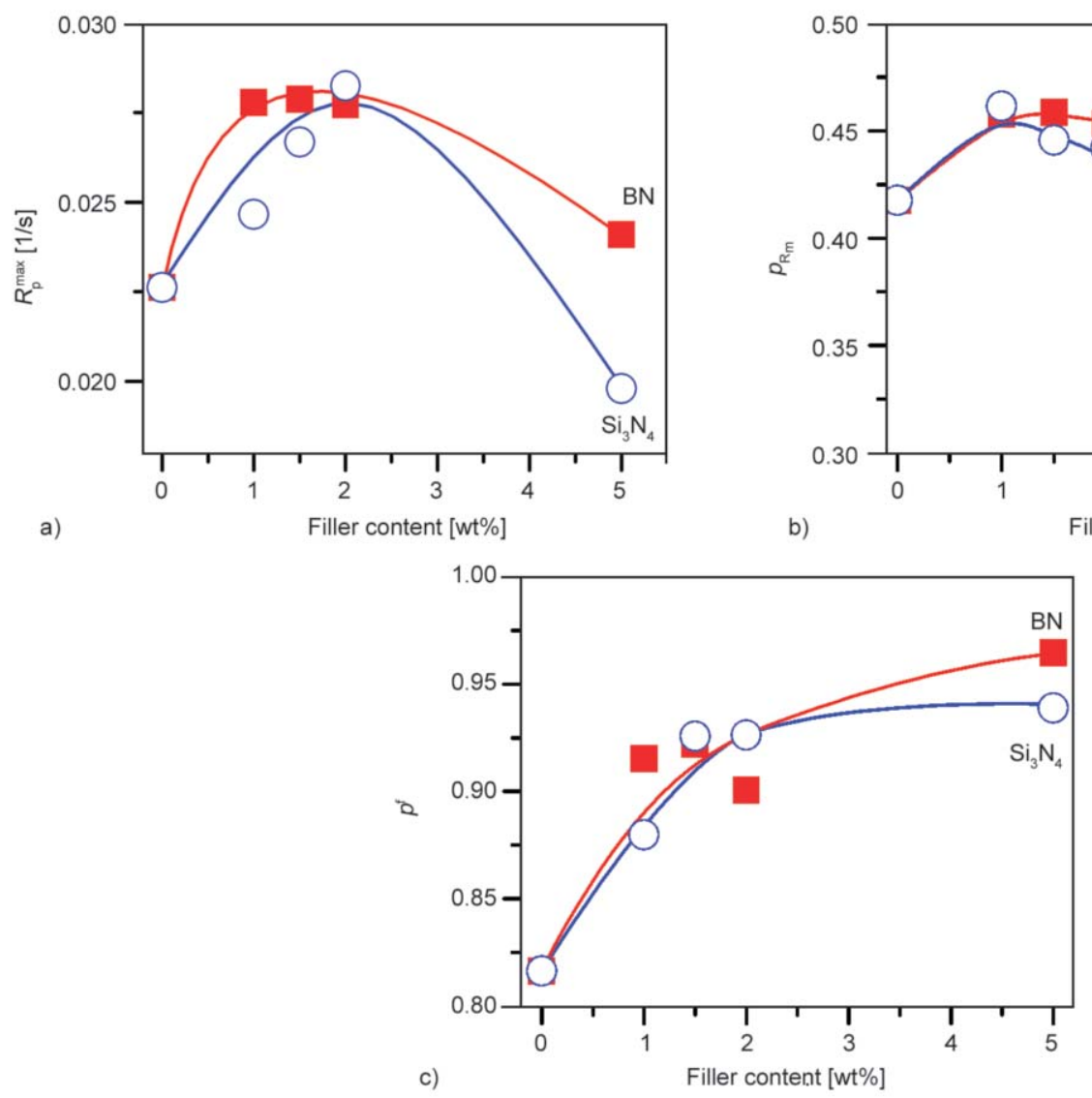

Figure 4. Maximum polymerization rate $R_{\mathrm{p}}^{\max }$ (a) double bond conversion at $R_{\mathrm{p}}^{\max }, p_{\mathrm{R}_{\mathrm{m}}}$ (b) and final conversion $p^{\mathrm{f}}$ (c) as functions of $\mathrm{BN}$ and $\mathrm{Si}_{3} \mathrm{~N}_{4}$ content (at $25^{\circ} \mathrm{C}$ ). The lines are guides for the eye. can lead both to suppression of termination and to acceleration of propagation [60]. Therefore, the increase in the $R_{\mathrm{p}}^{\max }$ in the presence of the fillers we can ascribe at least in part to suppression of termination caused by immobilization of macroradicals in the interphase zone; this needs, however, a good surface/polymer adhesion. Therefore, the decrease of $R_{\mathrm{p}}^{\max }$ could be associated with a decrease of the interphase volume at higher filler content, when greater aggregates are formed. These phenomena are reflected in the dependence of the final bond conversion pf on the filler content. Up to about $1 \%$ of its concentration $p^{\mathrm{f}}$ increases, but above this threshold value the further growth of $p^{\mathrm{f}}$ slows down. However, the fact that the $p^{\mathrm{f}}$ still slightly increases may suggest that system mobility (which determines $p^{f}$ value) also increases slightly. In both cases the final double bond conversion was high, on the order of $95 \%$.

Another factor that can affect the polymerization rate is refractive index ratio between the filler and the organic matrix. Ceramic particles limit UV penetration by scattering to a degree dependent on the refractive index contrast [61]. When the light is scattered, the effective intensity of the light absorbed is lower which

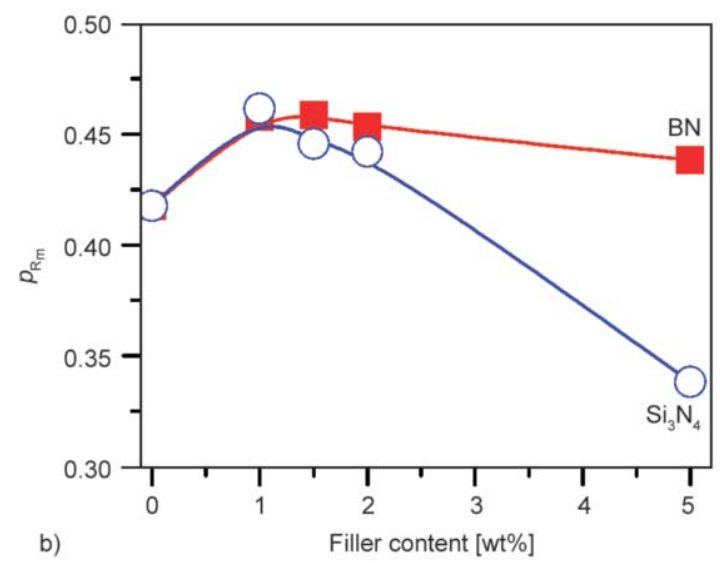

b) $\quad$ Filler content [wt $\%]$ 
leads to a decrease of the overall polymerization rate. $\mathrm{BN}(n=1.65$, Semiconductors properties database: http://www.ioffe.ru/SVA/) and $\mathrm{Si}_{3} \mathrm{~N}_{4}(n \sim 2.01$, Refractive index database: https://refractiveindex.info/) have some refractive index contrast with the monomers ( $n=1.467$, data from producer) which explains the opacity of the formulations. However, refractive index contrast in the case of $\mathrm{BN} /$ monomer mixture is lower than in the case of $\mathrm{Si}_{3} \mathrm{~N}_{4} /$ monomer mixture and this can be the reason of slightly faster polymerization of the former system.

\subsection{Glass transition}

The pure matrix is an elastomer with the glass transition temperature of $-36^{\circ} \mathrm{C}$. The introduction of the fillers has practically no effect on this parameter - its changes are negligible within $\left(2^{\circ} \mathrm{C}\right)$ indicating that filler particles do not significantly affect the movement of polymer chains.

\subsection{Thermal stability}

The influence of filler addition on the thermal stability of the polymer matrix was examined by TGA for samples containing $5 \mathrm{wt} \%$ of the fillers. Figure 5 shows TG and DTG curves of the pure matrix and the composites. The initial decomposition temperatures

Table 1. The results of thermal decomposition of the polymer matrix and composite materials.

\begin{tabular}{|l|c|c|}
\hline Filler & $\begin{array}{c}\boldsymbol{T}_{5}{ }^{\text {a }} \\
{\left[{ }^{\circ} \mathbf{C}\right]}\end{array}$ & $\begin{array}{c}\boldsymbol{R}^{\mathbf{b}} \\
{[\%]}\end{array}$ \\
\hline $\mathrm{No}$ & 270 & 1.27 \\
\hline $\mathrm{Si}_{3} \mathrm{~N}_{4}$ & 272 & 6.81 \\
\hline $\mathrm{BN}$ & 268 & 6.31 \\
\hline
\end{tabular}

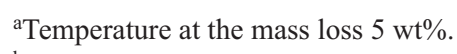

${ }^{b}$ Residual mass at $600{ }^{\circ} \mathrm{C}$.

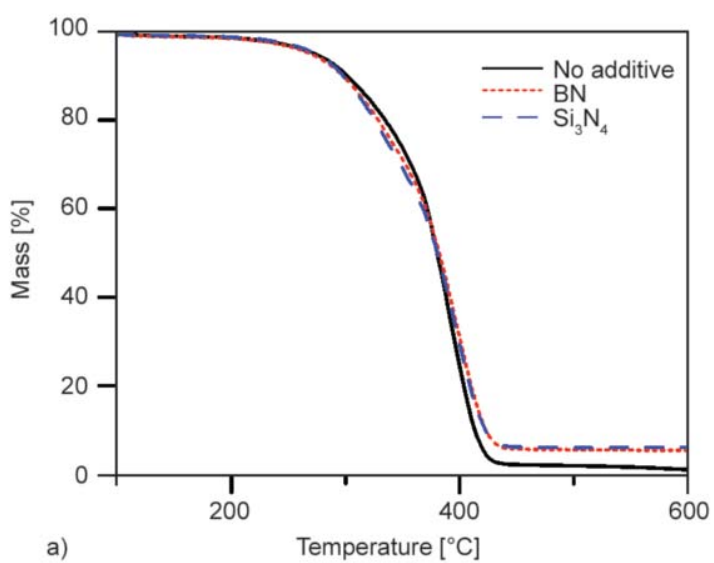

taken as $5 \%$ weight loss $\left(T_{5}\right)$ and the residual mass $R$ are given in Table 1 .

Decomposition of the pure matrix occurs in two main stages; the main chain scission is probably the major degradation path. Interestingly, the presence of the modifiers leads to a slight enhancement of the first decomposition stage, but the main degradation reaction undergoes retardation as can be concluded from the shift of the second decomposition peak to higher temperatures.

The onset of thermal decomposition in the presence of the fillers ( $T_{5}$ values) remains practically unchanged (Table 1). The residual mass of the pure matrix increases to the amount corresponding to the theoretical filler loading suggesting that the fillers do not hinder diffusion of gaseous decomposition products.

\subsection{Mechanical behavior}

Investigation of mechanical properties included determination of Young's modulus $(E)$, tensile strength $\left(\sigma_{\mathrm{M}}\right)$, elongation at break $\left(\varepsilon_{\mathrm{M}}\right)$ and hardness (Figure 6).

Despite the differences in the interactions of $\mathrm{BN}$ and $\mathrm{Si}_{3} \mathrm{~N}_{4}$ with the matrix, the mechanical behavior of their composites is similar. All the parameters, i.e. Young's modulus, tensile strength and hardness (except of elongation at break) increase monotonically with the filler content in the whole range studied. Addition of $5 \mathrm{wt} \%$ of $\mathrm{BN}$ or $\mathrm{Si}_{3} \mathrm{~N}_{4}$ increases $E$ and $\sigma_{\mathrm{M}}$ by $\sim 41$ and $\sim 50 \%$, respectively, demonstrating potential applications of $\mathrm{Si}_{3} \mathrm{~N}_{4}$ and $\mathrm{BN}$ for mechanical reinforcement. It is worth emphasizing that introduction of the fillers does not affect negatively the material ductility (no change in the elongation at break) despite increased Young's modulus. The increase of

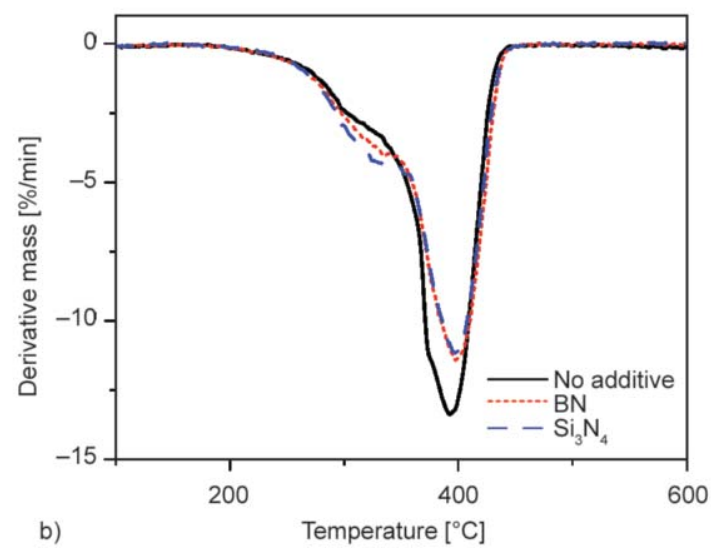

Figure 5. TG (a) and DTG (b) curves of the pure matrix and composites containing $5 \mathrm{wt} \%$ of the fillers. 

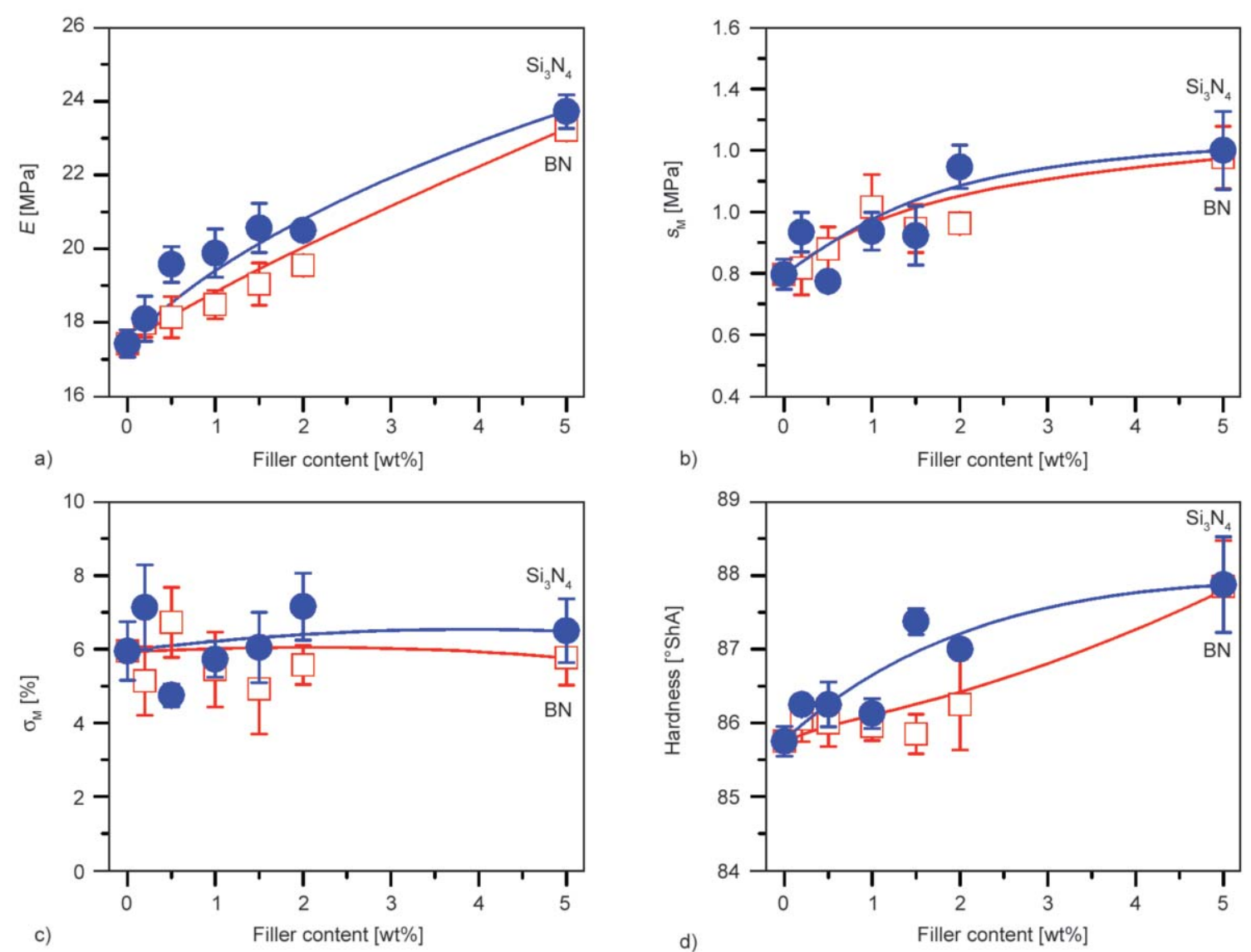

Figure 6. Young's modulus (a), tensile strength (b), elongation at break (c) and hardness (d) as a function of the filler content. The lines are guides to the eye.

hardness (by $\sim 2.5 \%$ ) results from the presence of hard boron and silica nitride particles. Somewhat better improvement of mechanical properties is observed in the case of $\mathrm{Si}_{3} \mathrm{~N}_{4}$, especially for Young's modulus and hardness.

\subsection{Thermal diffusivity and conductivity of the composites}

Figure 7 shows thermal diffusivity and conductivity of the investigated composites as functions of BN

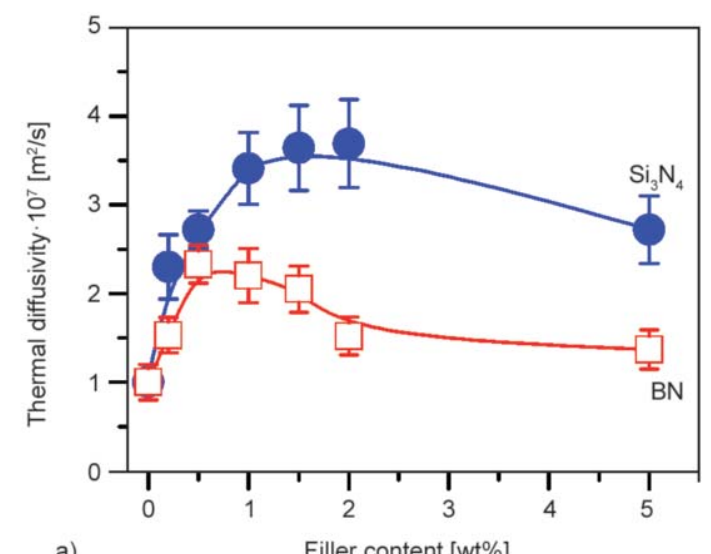

and $\mathrm{Si}_{3} \mathrm{~N}_{4}$ content. The behavior of the two types of composites is qualitatively similar: their thermal diffusivity/conductivity at first increases with the filler loading, reaches a maximum and then decreases. However, the heat diffusivity and conductivity values of $\mathrm{Si}_{3} \mathrm{~N}_{4}$-containing composites are about twice as high as these of $\mathrm{BN}$-containing composites. The maximum values of the discussed thermal parameters are reached at about $2 \mathrm{wt} \%$ of the filler content in the case of $\mathrm{Si}_{3} \mathrm{~N}_{4}$ and only at about $0.5 \mathrm{wt} \%$ for $\mathrm{BN}$

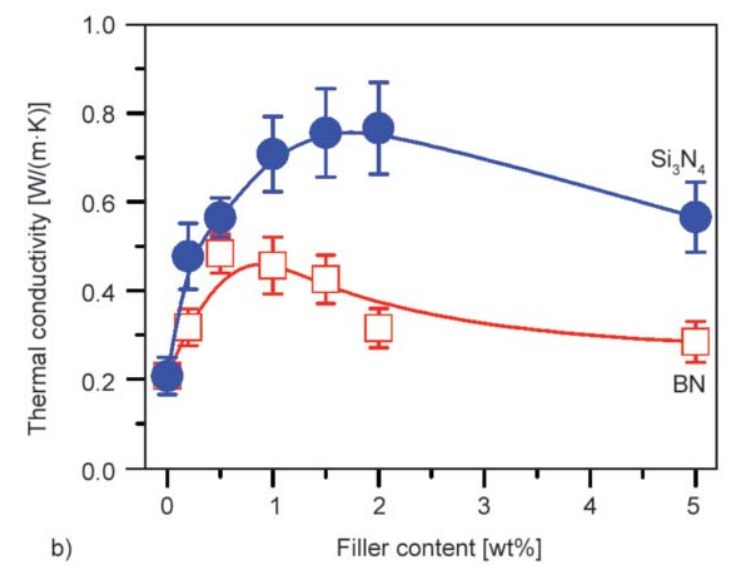

Figure 7. Thermal diffusivity (a) and thermal conductivity (b) of $\mathrm{BN}$ - and $\mathrm{Si}_{3} \mathrm{~N}_{4}$-containing composites as functions of the filler content. 
composites (a similar behavior was observed for an epoxy resin filled with graphene oxide [63]). The relative increase of the both parameters (as compared to the matrix) is quite high, about 4 times for $\mathrm{Si}_{3} \mathrm{~N}_{4}$ and about 2.5 times for $\mathrm{BN}$ indicating essential improvement of thermal properties.

The obtained results were verified in a separate set of measurements, using a different experimental method, for composites containing $5 \mathrm{wt} \%$ of the fillers. The values of thermal conductivity, $0.274 \mathrm{~W} /(\mathrm{m} \cdot \mathrm{K})$ for BN-containing and $0.392 \mathrm{~W} /(\mathrm{m} \cdot \mathrm{K})$ for $\mathrm{Si}_{3} \mathrm{~N}_{4}$-containing composites are in good agreement with the results presented in Figure 7.

While we were studying the photocurable nitridefilled formulations, the above-mentioned article describing photocured acrylate-based composites filled with surface modified BN appeared [48]. To obtain high conversion degree (95\%) the authors used a special initiating system. A significant enhancement of thermal conductivity was indicated (at $5 \%$ loading the increase reached about $50 \%$ ). It is worth to mention that in our work, using untreated fillers, we obtained at lower loadings much higher improvements (200-400\%), which in work [48] was reached at 35\% content of the modified BN. In addition, under our conditions the double conversion about $95 \%$ was reached using only a classical photoinitiator. This indicates that appropriate selection of the reaction conditions has a huge impact on the obtained conductivity results. Therefore, further investigation is needed, in which practical coating formulations will be used. It is also worth to mention that similar increases in thermal conductivity as in our work, up to about $0.8 \mathrm{~W} /(\mathrm{m} \cdot \mathrm{K}$ ), were reached also in other works (for various matrices, independently on $\mathrm{BN}$ modification or its state, e.g. exfoliation), but usually at much higher fillers contents, up to about $40 \%[48,62,64]$.

The observed behavior (dependence on filler content) and difference in conductivity of the two types of investigated composites may result from various factors, e.g. (i) differences in thermal conductivities of the fillers, (ii) differences in the particle size and shape, (iii) differences in the morphology of the composites.

Discussion of the first point is difficult because our suppliers do not specify thermal conductivities of the delivered nitrides. Considering the size and shape of the filler particles, it should be taken into account that the BN used by us is in the form of microparticles with platelet shape crystals forming aggregates, whereas
$\mathrm{Si}_{3} \mathrm{~N}_{4}$ particles are nanosized and spherical. It was indicated that composites with small filler particles have large interfacial area, causing phonon scattering and hindering its transport, which leads to a lower thermal conductivity [20]. Consequently, composites filled with larger particles have lesser filler/polymer interface and thus lower thermal interfacial resistance allowing for the improved heat conduction [65].

On the other hand, the nanoparticles may have different properties and different surface chemistry, which enables better dispersion in the composites. The influence of these parameters can dominate the reduced thermal interfacial resistance in microcomposites, which may result in higher thermal conductivity of composites filled with smaller particles [20]. This may explain the better thermal conductivity of our $\mathrm{Si}_{3} \mathrm{~N}_{4}$-filled composites.

An important parameter is also the thermal conductivity of the polymer matrix, especially, when the filler content is low, below the threshold level. Under such conditions the thermally conductive fillers are separated by the polymer matrix, which acts as a thermal barrier (the phonons are damped and scattered by the matrix reducing the inherent thermal conductivity of $\mathrm{BN}$ [62]) and becomes rate-limiting in the thermal conduction pathway. As will be shown below, in our composites the conducting paths have developed only partially and from a certain loading level $(\leq 2 \mathrm{wt} \%)$; further development was not continued (in the case of $\mathrm{Si}_{3} \mathrm{~N}_{4}$ ) or the conductive paths even worsened in the case of BN. This may suggest that at higher contents of the fillers their aggregates became larger which increased distances between the partly formed conducting paths.

Worse effective conductivity of the BN-filled composites can also results from interfacial thermal resistance between the matrix and the filler which hinders the transfer of phonon due to the phonon mismatch at the interface as a result of limited compatibility [62].

Another factor, which should be taken into account is the aspect ratio. Polymer composites loaded with fillers having low aspect ratio usually exhibit a lower thermal conductivity, whereas high-aspect-ratio fillers enable to reach the percolation threshold at lower concentrations [66]. BN belongs to fillers with high aspect ratio values (it will be also shown later on) but in the case of our composites this property seems to give no practical effect. In addition, with the increase of the BN contents, the relative disordered structure 
of fillers may decrease the efficiency of heat transmission along the in-plate direction, thus resulting in smaller increase in thermal conductivity [7].

\subsection{Morphology of the composites}

SEM images present a hexagonal $\mathrm{BN}$ with its flakelike morphology, i.e. laminated structure in which a large number of layers is organized in stacks (not shown). The size distribution 'in-plane' varies from $180 \mathrm{~nm}$ up to $\sim 13 \mu \mathrm{m}$, however, most to the sizes in the distribution are located approximately between 1.5 and $4 \mu \mathrm{m}$. The thickness is within the range of 16 and $280 \mathrm{~nm}$, and strongly depends on the 'in plane' size. We estimated the aspect ratio (the longest dimension divided by the shortest dimension, which is a thickness in this case) of BN particles to be between 11 and 46. Such high aspect ratio indeed indicates a strong size anisotropy for BN particles. SEM micrographs of $\mathrm{Si}_{3} \mathrm{~N}_{4}$ particles show regular spherical shape (not shown). The diameter distribution varies from 33 up to $69 \mathrm{~nm}$, with an average value of $51 \pm 9 \mathrm{~nm}$.

The low magnification SEM images show homogenously distributed $\mathrm{BN}$ particles in the matrix for all the filler contents; examples are shown in Figure 8. The polymer matrix represents smooth and featureless surface with terraces-like morphology that indicates the crack propagation plane of fractured samples (fractured at liquid nitrogen temperature). The dispersed particles, to a large extent, induce or terminate the crack propagation lines. The dispersion of $\mathrm{Si}_{3} \mathrm{~N}_{4}$ particles in the matrix was found to be good as well, however, locally aggregates were observed with sizes usually smaller than approximately $1-$ $2 \mu \mathrm{m}$. An aggregate representation is shown in the inset in Figure 9d.

High resolution SEM as well as AFM (height) imaging (Figure 9a and 9e) show smooth and flat free surface of the matrix (an averaged roughness, measured for a $10 \times 10 \mu \mathrm{m}^{2}$ AFM surface area is $5.5 \mathrm{~nm}$ ). The random copolymer structure is reflected by a single-phase morphology observed in both SEM and AFM images, and also in homogeneous Young's modulus maps (i.e., no color contrast in the image) in Figure 9i. An average surface Young's modulus of the matrix was calculated to be $27.9 \pm 0.8 \mathrm{MPa}$, based on collected force distance curves. This value seems to be overestimated by a $\sim 60 \%$ as compared to standard macro tensile testing (Figure 6a). One should, however, take into account that, despite the

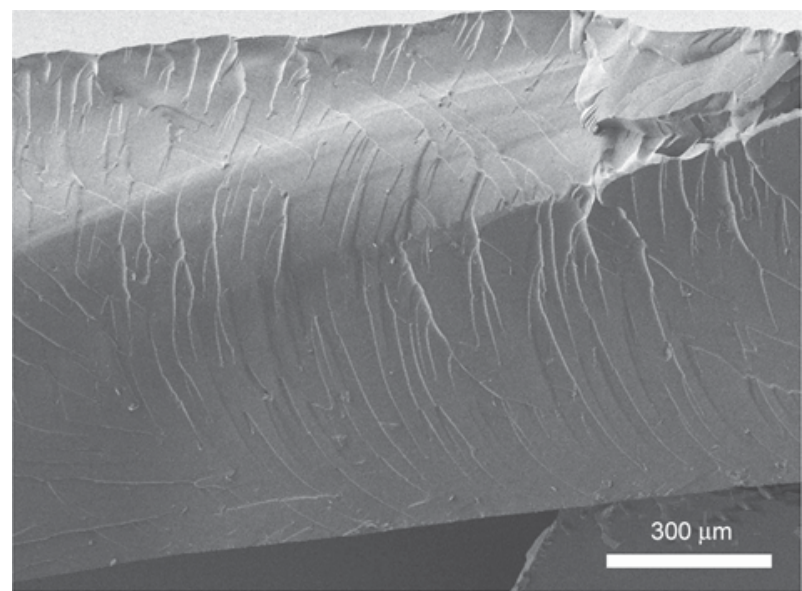

a)

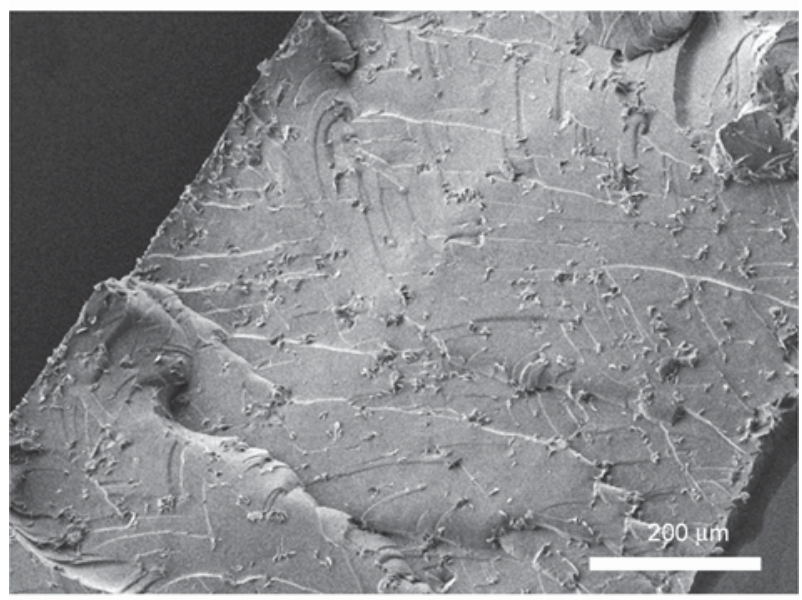

b)

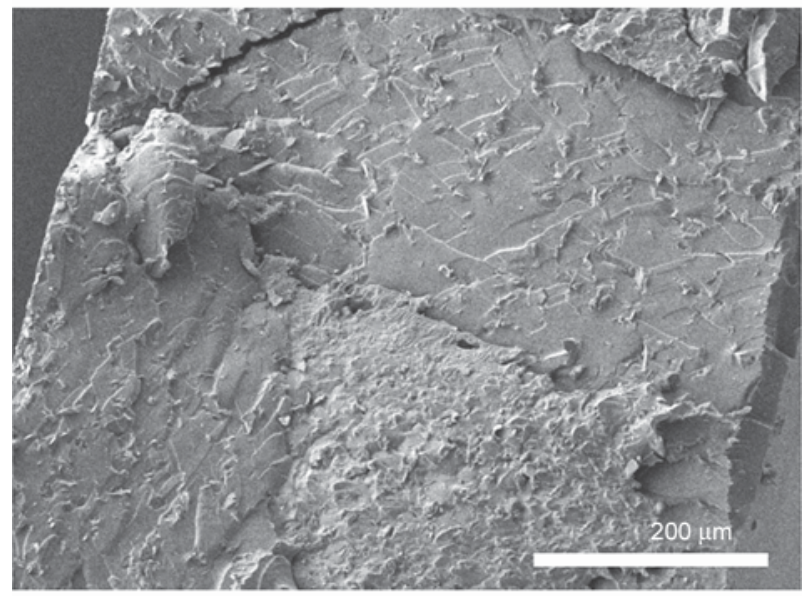

c)

Figure 8. SEM micrographs of fractured composites containing boron nitride particles. The filler content is (a) 1 , (b) 2 and (c) $5 \mathrm{wt} \%$.

uncertainty of the methods itself, some disagreement actually should appear in the moduli values due to differences in (i) the scale of the measurements (macro vs. nano), (ii) type of deformation (elongation vs. indentation) and (iii) models used (ISO standard vs. DMT model) reflecting different material property averaging $[56,67]$. 


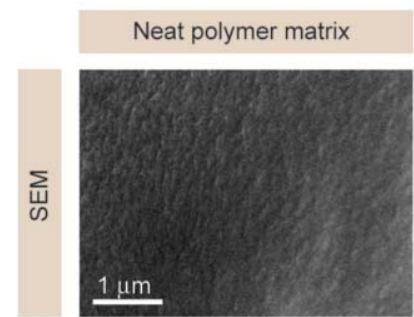

a)
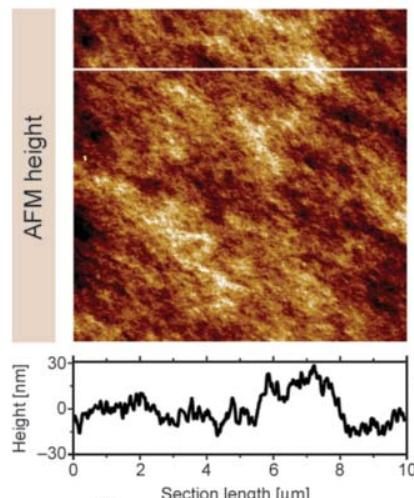

e)

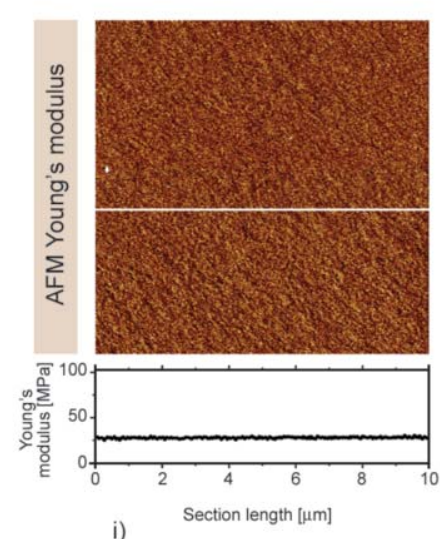

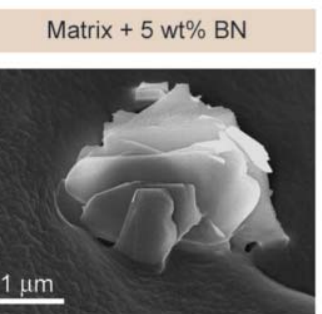

b)
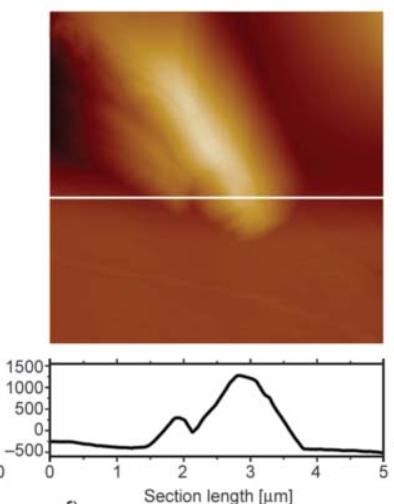

f)
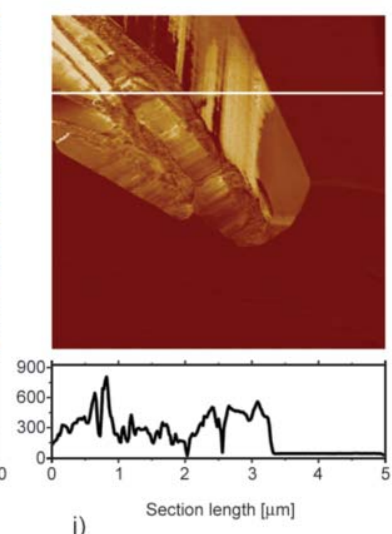

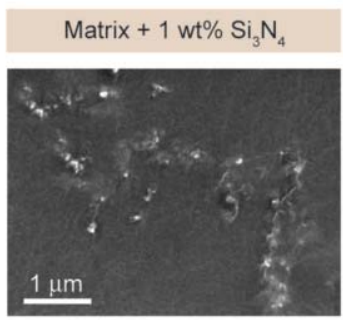

c)
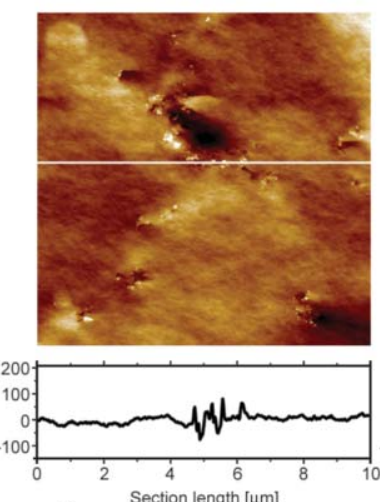

g)
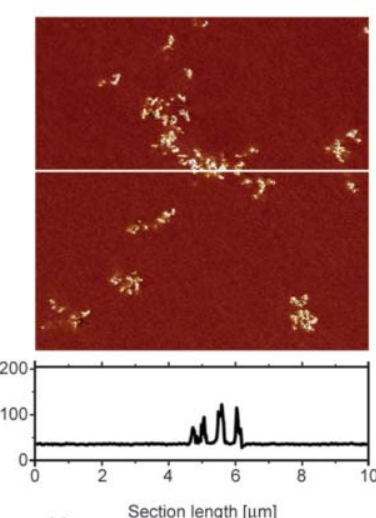

k)

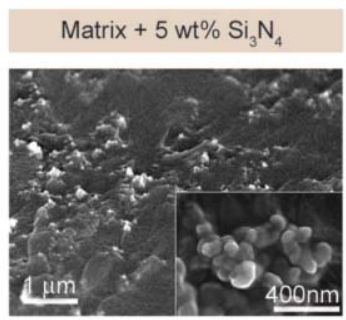

d)
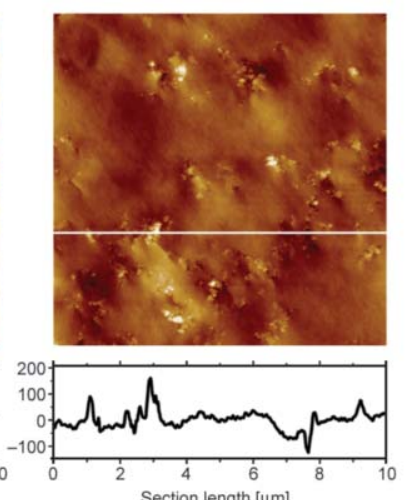

h)
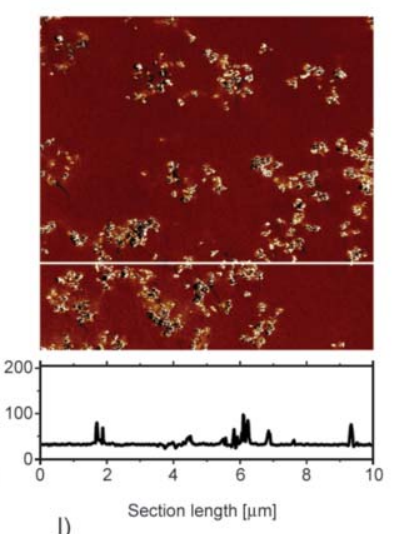

Figure 9. Graphical table containing free surface imaging by means of SEM and AFM (height and Young's modulus) for neat polymer matrix (a, e, i), matrix $+5 \mathrm{wt} \% \mathrm{BN}(\mathrm{b}, \mathrm{f}, \mathrm{j})$, matrix $+1 \mathrm{wt} \% \mathrm{Si}_{3} \mathrm{~N}_{4}(\mathrm{c}, \mathrm{g}, \mathrm{k})$, and matrix $+5 \mathrm{wt} \%$ $\mathrm{Si}_{3} \mathrm{~N}_{4}(\mathrm{~d}, \mathrm{~h}, \mathrm{l})$. The height- and modulus-profiles were taken along the white lines shown in the images and represent an overall topology and elasticity of the samples. An inset in (d) shows a typical representation of $\mathrm{Si}_{3} \mathrm{~N}_{4}$ particle aggregates.

Partly embedded BN particles (several flakes forming a small aggregate) in the polymer matrix are shown in the SEM image in Figure 9b. An AFM height representation on the BN filler 'immersed' in the copolymer matrix is shown in Figure 9f. The analysis of SEM images, also for other BN filler content, indicate that in the $\mathrm{BN}$-containing composites a significant wetting effect (large wetted length) was taking place at the Ar-matrix-particle interface (better visible in Figure 10). We believe that it was reflected by a capillary rise up the vertical sides of BN particles. This observation particularly demonstrate strong initial interactions between the particles and the polymer matrix (which are also manifested by the viscosity data in Figure 1a), that in turn resulted in a good

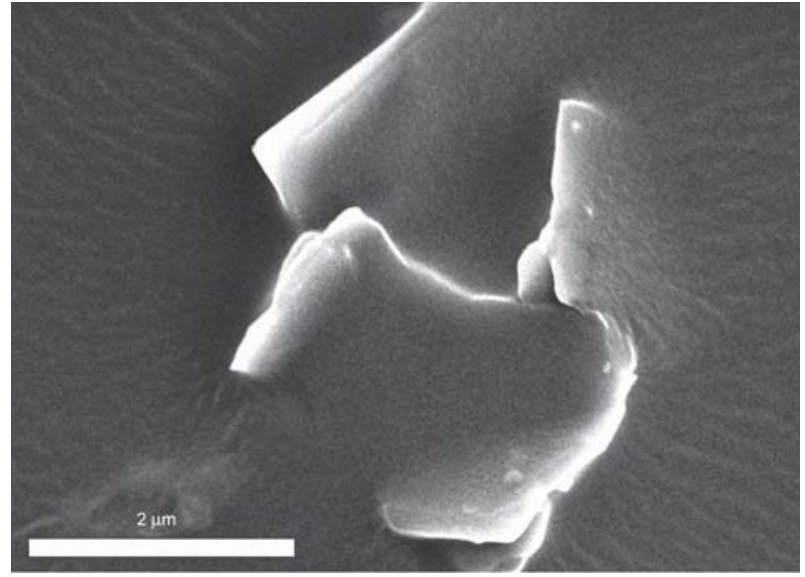

Figure 10. SEM picture showing the matrix morphology in the presence of the filler in the $\mathrm{BN}$-containing composites. The morphology is consistent with strong adhesion. 
matrix-particle adhesion in the final composites. Additionally, comparing the distribution of $\mathrm{BN}$ particles in the bulk (fractured samples, Figure 8) and at the surface (free surface, Figure 9b), one can find a higher ratio of the particle-per-area in the bulk than at the free surface. This observation again indicates good matrix-particle interactions; particles rather 'like' to be in the bulk than at the sample-air interface. We attribute the observed matrix-particle interactions as a main contributing factor to the heat sample transfer (poor adhesion would lead to scattering of the heat transfer). Favorable BN particles-matrix adhesion is also observed by AFM, namely via quantitative elasticity imaging (Figure 9j). We observed a coverage of the polymer matrix around of BN particles, forming a thin polymeric film. This feature was reflected by a low (below $0.9 \mathrm{GPa}$ ) Young's modulus value across the surface of BN particles (Figure 9j). Despite the fact of a good BN particle-matrix adhesion, a thermally conductive path of BN particles cannot be identified in any of our SEM or AFM images, even at $5 \mathrm{wt} \%$ of the filler content.

Free surface SEM (Figure 9c and 9d) and AFM height (Figure $9 \mathrm{~g}$ and $9 \mathrm{~h}$ ) images show typical $\mathrm{Si}_{3} \mathrm{~N}_{4}$ particle distribution at the sample interface for composites with 1 and $5 \mathrm{wt} \%$ of the filler. As found also for bulk samples (fractured specimens), the morphology unveils moderate aggregation tendencies between the $\mathrm{Si}_{3} \mathrm{~N}_{4}$ particles in the matrix; typically not larger than $\sim 2 \mu \mathrm{m}$ (see also inset in Figure 9d). Analysis of the distribution of $\mathrm{Si}_{3} \mathrm{~N}_{4}$ particles leads to a conclusion that they also tend to preferentially be located in the bulk, rather than at the interface; this indicates good $\mathrm{Si}_{3} \mathrm{~N}_{4}$ particles-matrix interactions (adhesion). The value of Young's modulus confirms this observation; it varies only up to maximum of about $200 \mathrm{MPa}$ across the particles (Figure 9k and 91) indicating polymeric interphase around the particles. Inspection on Figure 9k and 91 allows one to observe initiation of the formation of conductive paths - long and narrow aggregates/agglomerates of $\mathrm{Si}_{3} \mathrm{~N}_{4}$ particles. They are likely responsible for the improved thermal conductivity/diffusivity of the composites. However, these conductive paths are still separated by polymer matrix, which limits improvement of the conductivity. Much better results would be obtained if a continuous filler network was formed (above the percolation threshold). However, under the conditions used in our work, this was not achieved. To this end, further research is in progress.

\section{Conclusions}

Methacrylate-based composites with improved thermal conductivity were prepared by photocuring of monomer/(thermally conductive filler) compositions. Two types of filler were used: micro-sized flakeshaped hexagonal $\mathrm{BN}$ or nano-sized $\mathrm{Si}_{3} \mathrm{~N}_{4}$ with spherical particles.

The kinetic studies showed that the fillers used affected the curing process increasing the polymerization rate when the filler content increased up to about $1-2 \mathrm{wt} \%$; it can be ascribed to suppression of termination caused by immobilization of macroradicals in the interphase zone. At higher loadings the polymerization rate decreased, which is probably associated with a decrease of the interphase volume when greater aggregates are formed. The mechanical properties of the composites were improved compared to pure polymer matrix.

Despite the very low loading level (up to $5 \mathrm{wt} \%$ ) the composites containing $\mathrm{Si}_{3} \mathrm{~N}_{4}$ or $\mathrm{BN}$ particles showed significantly improved thermal diffusivity and conductivity compared to the pure matrix. The relative increase of the both parameters was about 4 times for $\mathrm{Si}_{3} \mathrm{~N}_{4}$ and about 2.5 times for BN. The maximum values of the discussed thermal parameters were reached at about $2 \mathrm{wt} \%$ of the filler content in the case of $\mathrm{Si}_{3} \mathrm{~N}_{4}$ and only at about $0.5 \mathrm{wt} \%$ for BN composites. Such a result (together with AFM data) suggests that the conducting paths have developed only partially and above these loading levels their further development was not continued. This can be associated with the formation of larger filler aggregates and increased distances between the partly formed conducting paths. Therefore, to further improve the conductivity, it is necessary to build longer conducting paths, preferably until reaching the percolation threshold, e.g. by changing the experimental conditions and/or by modification of the fillers.

SEM and AFM imaging showed good matrix-filler adhesion for the both types of fillers and the tendency of the particles to be preferentially located in the bulk rather than at the interface.

The results presented in this work are important from the point of view of industrial applications because this type of composites can be particularly suitable for production of protective coatings with improved thermal conductivity by widely used photopolymerization technique. 


\section{Acknowledgements}

This work was supported by the Research Projects of Poznan University of Technology 03/32/DSPB/0804 and 06/62/ DSPB/2183. H.G acknowledges the National Science Centre, Poland, for the project Miniatura no. 2017/01/X/ST5/00374. H.G. and G.J.V. acknowledge also the $\mathrm{MESA}^{+}$Institute of Nanotechnology at the University of Twente for funding. The SEM support by Rona Pitschke is gratefully appreciated.

\section{References}

[1] Xiao M., Du B. X.: Review of high thermal conductivity polymer dielectrics for electrical insulation. High Voltage, 1, 34-42 (2016).

https://doi.org/10.1049/hve.2016.0008

[2] Huang X., Jiang P., Tanaka T.: A review of dielectric polymer composites with high thermal conductivity. IEEE Electrical Insulation Magazine, 27, 8-16 (2011). https://doi.org/10.1109/MEI.2011.5954064

[3] Sangermano M., Razza N., Graham G., Barandiaran I., Kortaberria G.: Electrically insulating polymeric nanocomposites with enhanced thermal conductivity by visible-light curing of epoxy-boron nitride nanotube formulations. Polymer International, 66, 1935-1939 (2017). https://doi.org/10.1002/pi.5479

[4] Kochetov R., Andritsch T., Lafont U., Morshuis P. H. F., Smit J. J.: Thermal conductivity of nano-filled epoxy systems. in 'IEEE Conference on Electrical Insulation and Dielectric Phenomena, Virginia Beach, USA' 658661 (2009).

[5] Agrawal A., Satapathy A.: Epoxy composites filled with micro-sized AIN particles for microelectronic applications. Particulate Science and Technology, 33, 2-7 (2015). https://doi.org/10.1080/02726351.2014.919547

[6] Yu J., Mo H., Jiang P.: Polymer/boron nitride nanosheet composite with high thermal conductivity and sufficient dielectric strength. Polymers for Advanced Technologies, 26, 514-520 (2015).

https://doi.org/10.1002/pat.3481

[7] Shen H., Guo J., Wang H., Zhao N., Xu J.: Bioinspired modification of h-BN for high thermal conductive composite films with aligned structure. ACS Applied Materials and Interfaces, 7, 5701-5708 (2015). https://doi.org/10.1021/am507416y

[8] Qin L., Li G., Hou J., Yu X., Ding H., Zhang Q., Wang N., Qu X.: Preparation, characterization, and thermal properties of poly (methyl methacrylate)/boron nitride composites by bulk polymerization. Polymer Composites, 36, 1675-1684 (2015). https://doi.org/10.1002/pc.23078

[9] Ng H. Y., Lu X., Lau S. K.: Thermal conductivity of boron nitride filled thermoplastics: Effect of filler characteristics and composite processing conditions. Polymer Composites, 26, 778-790 (2005).

https://doi.org/10.1002/pc.20151
[10] Hong J-P., Yoon S-W., Hwang T., Oh J-S., Hong S-C., Lee Y., Nam J-D.: High thermal conductivity epoxy composites with bimodal distribution of aluminum nitride and boron nitride fillers. Thermochimica Acta, 537, 7075 (2012).

https://doi.org/10.1016/j.tca.2012.03.002

[11] Xu Y., Chung D. D. L., Mroz C.: Thermally conducting aluminum nitride polymer-matrix composites. Composites Part A: Applied Science and Manufacturing, 32, 1749-1757 (2001). https://doi.org/10.1016/S1359-835X(01)00023-9

[12] Zhou Y., Hyuga H., Kusano D., Yoshizawa Y-I., Ohji T., Hirao K.: Development of high-thermal-conductivity silicon nitride ceramics. Journal of Asian Ceramic Societies, 3, 221-229 (2015). https://doi.org/10.1016/j.jascer.2015.03.003

[13] Shi C., Zhu Y., Qian H., Lu L.: Fabrication of silicon nitride fiber-PMMA composite through free radical polymerization in batch. Materials Research Bulletin, 51, 161-166 (2014). https://doi.org/10.1016/j.materresbull.2013.12.010

[14] Xia R., Zhang Y., Zhu Q., Qian J., Dong Q., Li F.: Surface modification of nano-sized silicon nitride with BAMAA-AN tercopolymer. Journal of Applied Polymer Science, 107, 562-570 (2008).

https://doi.org/10.1002/app.26563

[15] Hong J., Yin S., Pan Y., Han J., Zhou T., Xu R.: Porous carbon nitride nanosheets for enhanced photocatalytic activities. Nanoscale, 6, 14984-14990 (2014).

https://doi.org/10.1039/c4nr05341a

[16] Kim J., Kim Y. D., Nam D. G., Bae J-S., Yeum J. H., Oh W.: Thermal properties of epoxy composites with silicon carbide and/or graphite. Journal of the Korean Physical Society, 68, 551-556 (2016). https://doi.org/10.3938/jkps.68.551

[17] Han Z., Fina A.: Thermal conductivity of carbon nanotubes and their polymer nanocomposites. A review. Progress in Polymer Science, 36, 914-944 (2011). https://doi.org/10.1016/j.progpolymsci.2010.11.004

[18] Chae S. H., Lee Y. H.: Carbon nanotubes and graphene towards soft electronics. Nano Convergence, 1, 15/1$15 / 26$ (2014). https://doi.org/10.1186/s40580-014-0015-5

[19] Shtein M., Nadiv R., Buzaglo M., Kahil K., Regev O.: Thermally conductive graphene-polymer composites: Size, percolation, and synergy effects. Chemistry of Materials, 27, 2100-2106 (2015). https://doi.org/10.1021/cm504550e

[20] Chen H., Ginzburg V. V., Yang J., Yang Y., Liu W., Huang Y., Du L., Chen B.: Thermal conductivity of polymer-based composites: Fundamentals and applications. Progress in Polymer Science, 59, 41-85 (2016). https://doi.org/10.1016/j.progpolymsci.2016.03.001 
[21] Falat T., Wymysłowski A., Kolbe J., Jansen K. M. B., Ernst L.: Influence of matrix viscoelastic properties on thermal conductivity of TCA - Numerical approach. Microelectronics Reliability, 47, 1989-1996 (2007). https://doi.org/10.1016/j.microrel.2007.04.010

[22] Li Z., Wu W., Chen H., Zhu Z., Wang Y., Zhang Y.: Thermal conductivity of micro/nano filler filled polymeric composites. RSC Advances, 3, 6417-6428 (2013). https://doi.org/10.1039/c3ra22482a

[23] Hou J., Li G., Yang N., Qin L., Grami M. E., Zhang Q., Wang N., Qu X.: Preparation and characterization of surface modified boron nitride epoxy composites with enhanced thermal conductivity. RSC Advances, 4, 44282-44290 (2014). https://doi.org/10.1039/C4RA07394K

[24] Cui X., Ding P., Zhuang N., Shi L., Song N., Tang S.: Thermal conductive and mechanical properties of polymeric composites based on solution-exfoliated boron nitride and graphene nanosheets: A morphology-promoted synergistic effect. ACS Applied Materials and Interfaces, 7, 19068-19075 (2015). https://doi.org/10.1021/acsami.5b04444

[25] Gu J., Lv Z., Wu Y., Guo Y., Tian L., Qiu H., Li W., Zhang Q.: Dielectric thermally conductive boron nitride/polyimide composites with outstanding thermal stabilities via in-situ polymerization-electrospinninghot press method. Composites Part A: Applied Science and Manufacturing, 94, 209-216 (2017).

https://doi.org/10.1016/j.compositesa.2016.12.014

[26] Kemaloglu S., Ozkoc., Aytac A.: Properties of thermally conductive micro and nano size boron nitride reinforced silicon rubber composites. Thermochimica Acta, 499, 40-47 (2010). https://doi.org/10.1016/j.tca.2009.10.020

[27] Zhou W.Y., Qi S.H., Zhao H.Z., Liu N.L.: Thermally conductive silicone rubber reinforced with boron nitride particle. Polymer Composite, 28, 23-28 (2007). https://doi.org/10.1002/pc.20296

[28] Shimamura A., Hotta Y., Hyuga H., Kondo N.,Hirao K.: Effect of amounts and types of silicon nitride on thermal conductivity of $\mathrm{Si}_{3} \mathrm{~N}_{4}$ /epoxy resin composite. Journal of the Ceramic Society of Japan, 123, 908-912 (2015) http://dx.doi.org/10.2109/jcersj2.123.908

[29] Rafiee M. A., Narayanan T. N., Hashim D. P., Sakhavand N., Shahsavari R., Vajtai R., Ajayan P. M.: Hexagonal boron nitride and graphite oxide reinforced multifunctional porous cement composites. Advanced Functional Materials, 23, 5624-5630 (2013). https://doi.org/10.1002/adfm.201203866

[30] Golberg D., Bando Y., Huang Y., Terao T., Mitome M., Tang C., Zhi C.: Boron nitride nanotubes and nanosheets. ACS Nano, 4, 2979-2993 (2010).

https://doi.org/10.1021/nn1006495
[31] Tanimoto M., Yamagata T., Miyata K., Ando S.: Anisotropic thermal diffusivity of hexagonal boron nitridefilled polyimide films: Effects of filler particle size, aggregation, orientation, and polymer chain rigidity. ACS Applied Materials and Interfaces, 5, 4374-4382 (2013). https://doi.org/10.1021/am400615z

[32] Tanaka T., Kozako M., Okamoto K.: Toward high thermal conductivity nano micro epoxy composites with sufficient endurance voltage. Journal of International Council on Electrical Engineering, 2, 90-98 (2014). https://doi.org/10.5370/JICEE.2012.2.1.090

[33] Madelung O., Rössler U., Schulz M.: Group IV elements, IV-IV and III-V compounds. Part A - Lattice properties. Springer, Berlin (2001).

https://doi.org/10.1007/b60136

[34] Couderc H., Vanga C., Fréchette M., David E.: Fabrication and dielectric properties of highly loaded polypropylene micro- and nano-composites. in 'IEEE Electrical Insulation Conference 2015. Seattle, USA' 238242 (2015).

https://doi.org/10.1109/ICACACT.2014.7223614

[35] Cheewawuttipong W., Fuoka D., Tanoue S., Uematsu H., Iemoto Y.: Thermal and mechanical properties of polypropylene/boron nitride composites. Energy Procedia, 34, 808-817 (2013). https://doi.org/10.1016/j.egypro.2013.06.817

[36] Cui M., Ren S., Chen J., Liu S., Zhang G., Zhao H., Wang L., Xue Q.: Anticorrosive performance of waterborne epoxy coatings containing water-dispersible hexagonal boron nitride (h-BN) nanosheets. Applied Surface Science, 397, 77-86 (2017).

https://doi.org/10.1016/j.apsusc.2016.11.141

[37] Yu C., Zhang J., Li Z., Tian W., Wang L., Luo J., Li Q., Fan X., Yao Y.: Enhanced through-plane thermal conductivity of boron nitride/epoxy composites. Composites Part A: Applied Science and Manufacturing, 98, 25-31 (2017).

https://doi.org/10.1016/j.compositesa.2017.03.012

[38] Hidayah I. N., Mariatti M., Ismail H., Kamarol M.: Effect of selective localization on dielectric properties of boron nitride nanofiller filled linear low density polyethylene (LLDPE)/silicone rubber (SR) blends. Polymer Testing, 56, 131-139 (2016).

https://doi.org/10.1016/j.polymertesting.2016.10.001

[39] Kim K., Ju H., Kim J.: Pyrolysis behavior of polysilazane and polysilazane-coated-boron nitride for high thermal conductive composite. Composites Science and Technology, 141, 1-7 (2017). https://doi.org/10.1016/j.compscitech.2017.01.003

[40] Wang C-A., Huang Y., Zan Q., Zou L., Cai S.: Control of composition and structure in laminated silicon nitride/boron nitride composites. Journal of the American Ceramic Society, 85, 2457-2461 (2002). https://doi.org/10.1111/j.1151-2916.2002.tb00480.x 
[41] Watari K.: High thermal conductivity non-oxide ceramics. Journal of the Ceramic Society of Japan, 109, S7S16 (2001).

https://doi.org/10.2109/jcersj.109.S7

[42] Hirosaki N., Ogata S., Kocer C., Kitagawa H., Nakamura Y.: Molecular dynamics calculation of the ideal thermal conductivity of single-crystal $\alpha$ - and $\beta-\mathrm{Si}_{3} \mathrm{~N}_{4}$. Physical Review B, 65, 134110/1-134110/11 (2002). https://doi.org/10.1103/PhysRevB.65.134110

[43] Zerr A., Kempf M., Schwarz M., Kroke E., Göken M., Riedel R.: Elastic moduli and hardness of cubic silicon nitride. Journal of the American Ceramic Society, 85, 86-90 (2002).

https://doi.org/10.1111/j.1151-2916.2002.tb00044.x

[44] Müller K., Bugnicourt E., Latorre M., Jorda M., Echegoyen Sanz Y., Lagaron J. M., Miesbauer O., Bianchin A., Hankin S., Bölz U., Pérez G., Jesdinszki M., Lindner M., Scheuerer Z., Castelló S., Schmid M.: Review on the processing and properties of polymer nanocomposites and nanocoatings and their applications in the packaging, automotive and solar energy fields. Nanomaterials, 7, 74/1-74/47 (2017). https://doi.org/10.3390/nano7040074

[45] Wang X., Pakdel A., Zhang J., Weng Q., Zhai T., Zhi C., Golberg D., Bando Y.: Large-surface-area BN nanosheets and their utilization in polymeric composites with improved thermal and dielectric properties. Nanoscale Research Letters, 7, 662/1-662/7 (2012). https://doi.org/10.1186/1556-276X-7-662

[46] Kul E., Aladağ L. İ., Yesildal R.: Evaluation of thermal conductivity and flexural strength properties of poly (methyl methacrylate) denture base material reinforced with different fillers. The Journal of Prosthetic Dentistry, 116, 803-810 (2016).

https://doi.org/10.1016/j.prosdent.2016.03.006

[47] Sadej M., Andrzejewska E.: Silica/aluminum oxide hybrid as a filler for photocurable composites. Progress in Organic Coatings, 94, 1-8 (2016). https://doi.org/10.1016/j.porgcoat.2016.01.008

[48] Goldin N., Dodiuk H., Lewitus D.: Enhanced thermal conductivity of photopolymerizable composites using surface modified hexagonal boron nitride fillers. Composites Science and Technology, 152, 36-45 (2017). https://doi.org/10.1016/j.compscitech.2017.09.001

[49] Drin' A. P., Efanova V. V., Shut N. I.: Thermal conductivity and kinetics of polymerization of an acrylate polymer coating. Journal of Engineering Physics and Thermophysics, 66, 164-171 (1994). https://doi.org/10.1007/BF00862717

[50] Andrzejewska E., Marcinkowska A., Wegner K.: Nanocomposites obtained by photopolymerization of (methacrylate monomer)/(methacrylate functionalized polyhedral oligomeric silsesquioxane) system. Polimery, 56, 63-66 (2011).
[51] Jakubowska P., Sterzyński T.: Thermal diffusivity of polyolefin composites highly filled with calcium carbonate. Polimery, 57, 271-275 (2012). https://oi.org/10.14314/polimery.2012.271

[52] Agarwal K. N., Verma V. V.: A quick method of measuring thermal conductivity and thermal diffusivity of building fabrics. Building Science, 2, 165-172 (1967).

https://doi.org/10.1016/0007-3628(67)90016-3

[53] PeakForce QNM User Guide, Bruker (2011).

[54] Hutter J. L., Bechhoefer J.: Calibration of atomic-force microscope tips. Review of Scientific Instruments, 64, 1868-1873 (1993).

https://doi.org/10.1063/1.1143970

[55] Sader J. E., Larson I., Mulvaney P., White L. R.: Method for the calibration of atomic force microscope cantilevers. Review of Scientific Instruments, 66, 37893798 (1995). https://doi.org/10.1063/1.1145439

[56] Gojzewski H., Imre B., Check C., Chartoff R., Vancso J.: Mechanical mapping and morphology across the length scales unveil structure-property relationships in polycaprolactone based polyurethanes. Journal of Polymer Science Part B: Polymer Physics, 54, 2298-2310 (2016). https://doi.org/10.1002/polb.24140

[57] Derjaguin B. V., Muller V. M., Toporov Y. P.: Effect of contact deformations on the adhesion of particles. Journal of Colloid and Interface Science, 53, 314-326 (1975).

https://doi.org/10.1016/0021-9797(75)90018-1

[58] Andrzejewska E.: Photopolymerization kinetics of multifunctional monomers. Progress in Polymer Science, 26, 605-665 (2001). https://doi.org/10.1016/S0079-6700(01)00004-1

[59] Andrzejewska E.: Termination mechanism in photoinitiated radical crosslinking polymerization. in 'Recent research developments in applied polymer science' (ed.: Pandalai S. G.) Research Signpost, Trivandrum, Vol. 7, 247-270 (2003).

[60] Sadej M., Andrzejewska E., Kurc B., Gojzewski H., Jesionowski T.: Surface dependent effect of functional silica fillers on photocuring kinetics of hydrogel materials. Journal of Polymer Science Part A: Polymer Chemistry, 52, 3472-3487 (2014).

https://doi.org/10.1002/pola.27412

[61] Halloran J. W., Tomeckova V., Gentry S., Das S., Cilino P., Yuan D., Guo R., Rudraraju A., Shao P., Wu T., Alabi T. R., Baker W., Legdzina D., Wolski D., Zimbeck W. R., Long D.: Photopolymerization of powder suspensions for shaping ceramics. Journal of the European Ceramic Society, 31, 2613-2619 (2011). https://doi.org/10.1016/j.jeurceramsoc.2010.12.003

[62] Zeng X., Yu S., Sun R.: Thermal behavior and dielectric property analysis of boron nitride-filled bismaleimidetriazine resin composites. Journal of Applied Polymer Science, 128, 1353-1359 (2013). https://doi.org/10.1002/app.38276 
[63] Zhou T., Koga H., Nogi M., Sugahara T., Nagao S., Nge T. T., Suganuma K., Cui H-W., Liu F., Nishina Y.: Targeted kinetic strategy for improving the thermal conductivity of epoxy composite containing percolating multi-layer graphene oxide chains. Express Polymer Letters, 9, 608-623 (2015).

https://doi.org/10.3144/expresspolymlett.2015.57

[64] Zhang Y., Choi J. R., Park S-J.: Thermal conductivity and thermo-physical properties of nanodiamond-attached exfoliated hexagonal boron nitride/epoxy nanocomposites for microelectronics. Composites Part A: Applied Science and Manufacturing, 101, 227-236 (2017). https://doi.org/10.1016/j.compositesa.2017.06.019
[65] Tsutsumi N., Takeuchi N., Kiyotsukuri T.: Measurement of thermal diffusivity of filler-polymide composites by flash radiometry. Journal of Polymer Science Part B: Polymer Physics, 29, 1085-1093 (1991). https://doi.org/10.1002/polb.1991.090290907

[66] Tao Y., Yang Z., Lu X., Tao G., Xia Y., Wu H.: Influence of filler morphology on percolation threshold of isotropical conductive adhesives (ICA). Science China, Technological Sciences, 55, 28-33 (2012). https://doi.org/10.1007/s11431-011-4651-2

[67] Gojzewski H., Sadej M., Andrzejewska E., Kokowska M.: Nanoscale Young's modulus and surface morphology in photocurable polyacrylate/nanosilica composites. European Polymer Journal, 88, 205-220 (2017). https://doi.org/10.1016/j.eurpolymj.2017.01.022 